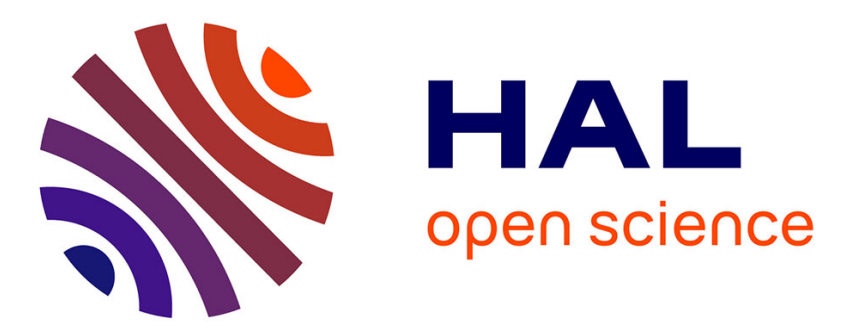

\title{
The Role of Viscoelastic Stress Transfer in Long-Term Earthquake Cascades: Insights After the Central Italy 2016-2017 Seismic Sequence
}

\author{
A. Verdecchia, B. Pace, F. Visini, O. Scotti, L. Peruzza, Lucilla Benedetti
}

\section{- To cite this version:}

A. Verdecchia, B. Pace, F. Visini, O. Scotti, L. Peruzza, et al.. The Role of Viscoelastic Stress Transfer in Long-Term Earthquake Cascades: Insights After the Central Italy 2016-2017 Seismic Sequence. Tectonics, 2018, 37 (10), pp.3411-3428. 10.1029/2018TC005110 . hal-01934256

\author{
HAL Id: hal-01934256 \\ https://hal.science/hal-01934256
}

Submitted on 3 Dec 2019

HAL is a multi-disciplinary open access archive for the deposit and dissemination of scientific research documents, whether they are published or not. The documents may come from teaching and research institutions in France or abroad, or from public or private research centers.
L'archive ouverte pluridisciplinaire HAL, est destinée au dépôt et à la diffusion de documents scientifiques de niveau recherche, publiés ou non, émanant des établissements d'enseignement et de recherche français ou étrangers, des laboratoires publics ou privés. 


\section{Tectonics}

\section{RESEARCH ARTICLE}

10.1029/2018TC005110

\section{Special Section:}

The 2016 Central Italy Seismic Sequence: Insights, implica-

tions and lessons learned

\section{Key Points:}

- Earthquake cascades in Central Italy are controlled by both coseismic and postseismic Coulomb stress changes

- The Gorzano fault and several other faults capable of $M_{w} \geq 6$ have been strongly loaded by the 1915-2016 sequence

- Coseismic and postseismic Coulomb stress changes should be considered in probabilistic seismic hazard calculations

Supporting Information:

- Supporting Information S1

Correspondence to:

A. Verdecchia,

alessandro.verdecchia@rub.de

Citation:

Verdecchia, A., Pace, B., Visini, F., Scotti, O., Peruzza, L., \& Benedetti, L. (2018). The role of viscoelastic stress transfer in long-term earthquake cascades: Insights after the Central Italy 2016-2017 seismic sequence. Tectonics, 37. https://doi.org/10.1029/ 2018TC005110

Received 17 APR 2018

Accepted 7 SEP 2018

Accepted article online 13 SEP 2018

2018. American Geophysical Union. All Rights Reserved.

\section{The Role of Viscoelastic Stress Transfer in Long-Term Earthquake Cascades: Insights After the Central Italy 2016-2017 Seismic Sequence}

\author{
A. Verdecchia' ${ }^{1 D}$, B. Pace ${ }^{2}$, F. Visini ${ }^{3}$, O. Scotti ${ }^{4}$ (D) L. Peruzza ${ }^{5}$, and L. Benedetti ${ }^{6}$ \\ ${ }^{1}$ Institute of Geology, Mineralogy and Geophysics, Ruhr-University Bochum, Bochum, Germany, ${ }^{2}$ CRUST-DiSPUTer, \\ Università G. d'Annunzio di Chieti-Pescara, Chieti, Italy, ${ }^{3}$ Istituto Nazionale di Geofisica e Vulcanologia, Sezione di Pisa, Italy, \\ ${ }^{4}$ Institut de Radioprotection et de Sureté Nucléaire IRSN, Fontenay-aux-Roses, France, ${ }^{5}$ Istituto Nazionale di Oceanografia e \\ di Geofisica Sperimentale-OGS, Sgonico, TS, Italy, ${ }^{6}$ CEREGE CNRS-IRD UMR 34, Aix-Marseille Université, Aix en Provence, \\ France
}

Abstract Central Italy is characterized by a network of active faults that interact in a complex manner. Coseismic Coulomb stress changes have been invoked by several authors to explain the concentration of moderate-to-strong earthquakes in this region, but none has considered the time-dependent viscoelastic relaxation of the lower crust and upper mantle as a possible additional source of stress changes at a regional scale. Here starting from the $1915 M_{\mathrm{w}} 6.9 \pm 0.2$ Fucino earthquake, we calculated the coseismic plus postseismic Coulomb failure stress changes ( $\triangle$ CFS) due to eight moderate-to-strong earthquakes that have struck Central Italy in the last century and culminated with the 2016-2017 sequence. Results from this modeling coupled with some synthetic tests simulating normal fault earthquakes with different magnitudes allowed us to highlight the importance of postseismic processes. In particular, the viscoelastic stress transfer due to events of $M_{\mathrm{w}} \geq 6.5$ can modify the spatial distribution of $\Delta$ CFS on a centennial timescale and therefore trigger events at larger distances. In addition, using these results, we identified other earthquake clusters in the historical catalogue (last 618 years), which, like the 1915-2017 series, were potentially modulated by both coseismic and postseismic processes. Finally, considering our calculations combined with historical and paleoseismological data, we suggest that several faults in Central Italy may be at present close to failure.

\section{Introduction}

Understanding the processes that control the space-time distribution of earthquakes, besides being a challenging and still open debate, is essential to better assess seismic hazard in any region. In 2016 and 2017, Central Italy experienced a sequence of damaging earthquakes in the complex normal faulting system of the Central Apennines (Chiaraluce et al., 2017, and references therein), causing 299 casualties. To date, the last moderate events of the sequence (four $M_{\mathrm{w}}>5.5$ occurred on 18 January 2017) were located along the central and southern portions of the Gorzano fault (Chiaraluce et al., 2017). The 2016 sequence was located about $20 \mathrm{~km}$ south of the 1997 Colfiorito sequence (a $M_{\mathrm{w}} 5.7$ and a $M_{\mathrm{w}} 6.0$ on 26 September and a $M_{\mathrm{w}} 5.6$ on 14 October) and less than $50 \mathrm{~km}$ north of the area struck during the 2009 L'Aquila earthquake $\left(M_{\mathrm{w}}\right.$ 6.3). The 2016 sequence thus apparently partially filled a gap between the 1997 and the 2009 earthquake sequences. Could those events belong to the same long-term sequence of events? Which processes promote such sequences? Can we develop models that account for such processes and eventually improve earthquake forecasts used in seismic hazard assessment?

Since the early 1990s, elastic interactions between simultaneously growing faults have been proposed as key ingredients in the self-organization of fault patterns in the lithosphere (A. Sornette et al., 1990; D. Sornette et al., 1990). Using such self-organized models, combined with Coulomb stress transfer considerations, Cowie (1998) demonstrated that stress feedback mechanisms between adjacent faults play a key role in the accumulation of displacement through time. Today, such modeling results are supported by a growing sample of field observations that demonstrate long-term variations in fault displacement rates and alternating periods of activity and quiescence (e.g., Benedetti et al., 2013; Dolan et al., 2016; Friedrich et al., 2003; Scholz, 2010; Sieh et al., 2008). More recently, advances in high-resolution topography, and Quaternary dating tools, have led many authors to suggest that transient fault slip rates and irregular earthquake recurrence intervals may be a common feature even at the 1,000-year timescale (e.g., Gold et al., 2017; 
Schlagenhauf et al., 2011; Wedmore et al., 2017, and references therein). The development of methods, at the 1,000- to 100-year timescale, that can account for such earthquake recurrence variability in seismic hazard assessment has been the objective of many authors since the mid-1990s (e.g., Console et al., 2008; Robinson, 2004; Stein et al., 1997; Visini \& Pace, 2014, among many others); however postseismic processes due to viscoelastic relaxation are rarely considered (see Verdecchia and Carena, 2016, and references therein).

The hypothesis explored in this paper is that the irregularity of earthquake recurrence intervals observed in Central Italy (Benedetti et al., 2013; Faenza et al., 2004) may be partly due to stress feedback mechanisms that occur not only in the crust (Wedmore et al., 2017) but also in the ductile layers below. In such a context, the question we would like to address is the extent to which long-range interaction processes (i.e., viscoelastic relaxation) play a role, since the stress perturbations they induce in the upper crust, following major earthquakes, exceed in spatial extent those due to Coulomb coseismic static stress perturbations commonly invoked (see Harris and Simpson, 1998, for a review).

Viscoelastic relaxation of the lower crust and upper mantle has been invoked to explain the delayed triggering of many major earthquakes in California, Japan, and Mongolia (DeVries et al., 2016, and references therein). The coupling between the near surface elastic and brittle crust and the underlying viscous layers has also been shown to play a major role in influencing the spatial pattern of faulting in continental regions (e.g., Verdecchia \& Carena, 2016). Numerical modeling underlined the key role of the relative strength of the brittle and ductile layers (parameterized by means of density, thickness, viscosity, and imposed strain rate) in controlling the development and linkage of a fault network (Bhat et al., 2007; Biemiller \& Lavier, 2017). In such models, the fault stress perturbations remain limited to the fault rupture extent in the presence of a ductile layer that is stronger than the brittle layer, facilitating the creation of many new faults as the strain progresses. Conversely, if the lower layer is weak compared to the elastic/brittle layer, then the deformation localizes onto the few major initial fault zones that are established at the start of the simulation (Davy et al., 1995).

In order to examine whether viscoelastic Coulomb stress interactions in a layered lithosphere may help in understanding the observed space-time clustering of the moderate magnitude events in peninsular Italy (Figure 1), we proceed in three different steps. First, we compute the time-dependent (coseismic plus postseismic) Coulomb stress changes due to three synthetic normal fault earthquakes with different magnitudes. This allows us to define possible relationships between the magnitude of the events and the space-time patterns of positive stress changes that would promote failure on other faults. In the second part of this study, these relationships are used to identify possible clusters of events along the Apennines. Finally, among the defined clusters, we focus on the most recent one, the sequence of events that occurred in the Central Apennine between the major $1915 M_{\mathrm{w}} 6.9$ Fucino earthquake up to the moderate-to-large events of the 2016-2017 Central Italy sequence. The 1915 earthquake is one of the largest events to have occurred in Central Italy, and the determination of its magnitude is the focus of several studies. Taking in consideration both the moment magnitude suggested by the historical catalogue (obtained by macroseismic felt intensities inversion, $M_{\mathrm{w}} \sim 7$ in CPTI15; Rovida et al., 2016) and by the work of Amoruso et al. (1998; $M_{\mathrm{w}} 6.7$ from inversion of geodetic and seismic data), here we use a value of $M_{\mathrm{w}}$ 6.9, consistent with the coseismic slip distribution obtained by Paolucci et al. (2016). The ultimate aims of this study are, on the one hand, to quantify the present-day stress perturbations along the fault system activated by the 2016-2017 earthquake sequence, with a specific focus on the Gorzano segment, and on the other hand, to highlight the specificity of the central Italian Apennine seismicity, characterized by long- and short-term clusters of events potentially governed in part by viscoelastic processes triggered in the wake of major earthquakes.

\section{Method}

\subsection{Coulomb Stress Changes}

The concept of Coulomb stress changes has been extensively applied in the past two decades to explore the spatial and temporal relationship among active faults (e.g., Harris \& Simpson, 1998; King et al., 1994; Ma et al., 2005; Marsan, 2003; Parsons et al., 2000; Stein, 1999; Stein et al., 1994, 1997; Toda et al., 2008).

The change in Coulomb failure stress ( $\triangle \mathrm{CFS}$ ) due to an earthquake on a so-called source fault is given by 


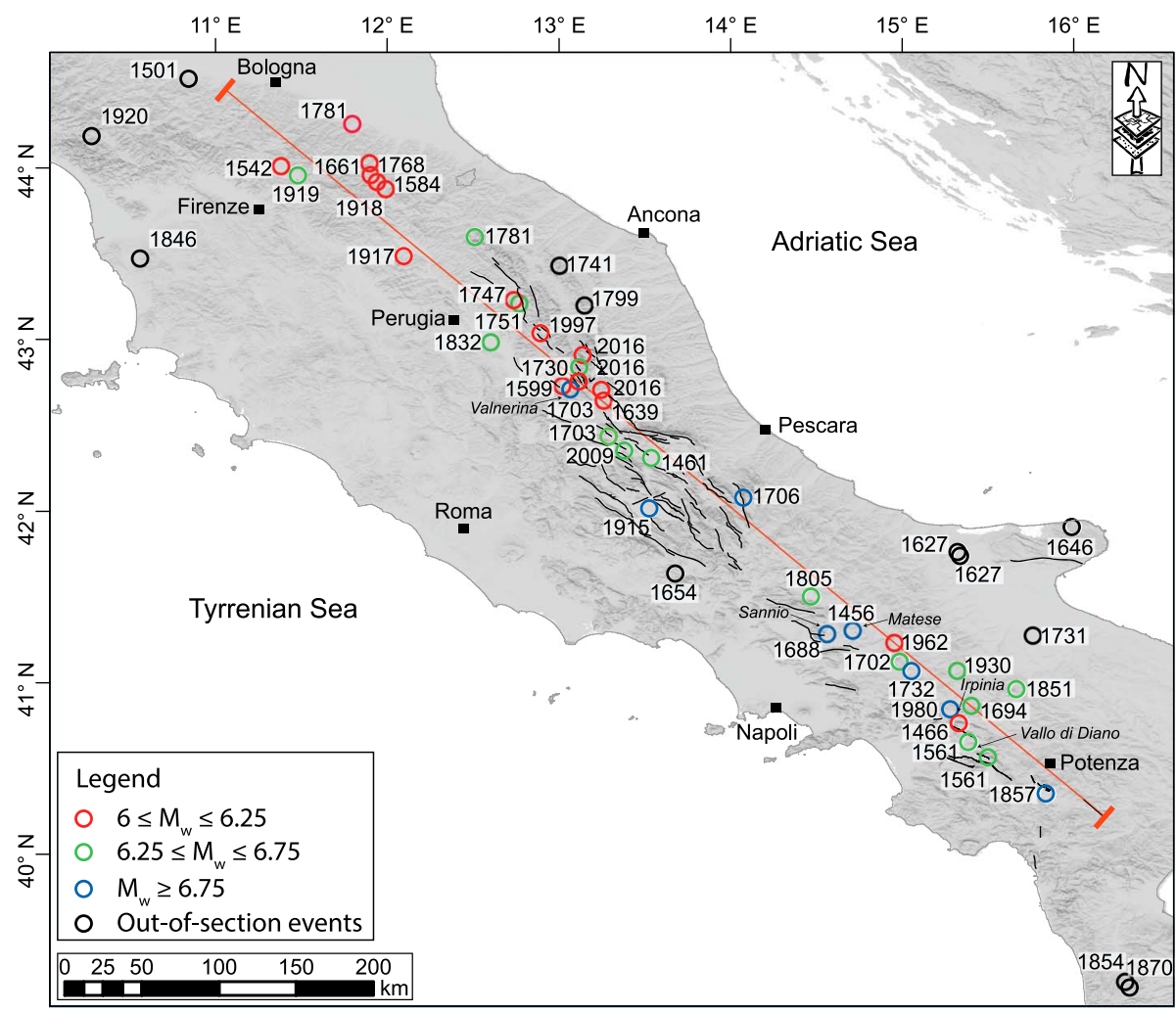

Figure 1. Map of $M_{\mathrm{w}} \geq 6$ historical earthquakes along the Apennine mountain chain starting from $1400 \mathrm{CE}$ (from the catalogue CPTI15; Rovida et al., 2016). Black empty circles represent the events located outside the 30-km half width along the trace of the section (red dashed line) and not considered in Figure 3. Black lines represent the main active faults in the study region (Benedetti, 1999; Benedetti et al., 2013). No active faults are shown north of Perugia.

$$
\Delta \mathrm{CFS}=\Delta \tau-\mu^{\prime} \Delta \sigma_{n}
$$

where $\Delta \tau$ is the change in shear stress along a specific slip vector, $\mu^{\prime}$ is the coefficient of effective friction, and $\Delta \sigma_{n}$ is the change in normal stress; stresses are calculated for so-called receiver faults, with the orientation and kinematics of optimally oriented planes, or set up on specified faults. Positive changes encourage failure and thus increase the likelihood of an earthquake, while negative changes inhibit failure and decrease the likelihood of an event.

In addition to a time-independent static (coseismic) approach, a time-dependent quasi-static (postseismic) modeling has been often used to explain earthquake interactions at different timescales (Freed, 2005). Postseismic calculations take into account the redistribution of Coulomb stress due to viscoelastic relaxation of the lower crust and the upper mantle, which according to several authors (e.g., Ali et al., 2008; Chéry et al., 2001; Lorenzo-Martín et al., 2006; Pollitz et al., 2003; Shan et al., 2013; Verdecchia \& Carena, 2015, 2016) plays an important role in earthquake triggering at timescales longer than 5 years. In this study, we operate at a secular timescale and thus use the multilayered viscoelastic half-space code PSGRN/PSCMP (Wang et al., 2006) to calculate both coseismic and postseismic stress changes. Clearly, tectonic loading drives the occurrence of earthquakes and is thus the primary source of stress accumulation on faults at the seismic cycle timescale. However, here we focus on the interaction among earthquakes and therefore the perturbation to the long-term loading, and so we therefore did not calculate interseismic $\Delta C F S$.

\subsection{Coseismic Versus Postseismic Sensitivity Tests}

The PSGRN/PSCMP code has been designed to calculate coseismic and postseismic strain and stresses induced by any earthquakes. In addition to the standard input needed for static Coulomb stress changes modeling codes (e.g., Coulomb 3.3; Toda et al., 2011), it requires a rheological model for the lithosphere. In 
Table 1

Combinations of Tested Crust and Mantle Viscosities ( $\eta$ )

\begin{tabular}{|c|c|c|c|c|c|c|c|c|c|c|}
\hline & $\begin{array}{c}\text { Thickness }{ }^{a} \\
(\mathrm{~km})\end{array}$ & $\begin{array}{c}V_{p}^{a} \\
(\mathrm{~km} / \mathrm{s})\end{array}$ & $\begin{array}{c}V_{\mathrm{s}}^{\mathrm{a}} \\
(\mathrm{km} / \mathrm{s})\end{array}$ & $\begin{array}{c}\rho^{\mathrm{a}} \\
\left(\mathrm{kg} / \mathrm{m}^{3}\right)\end{array}$ & $\begin{array}{l}\text { Model } 1 \eta \\
\quad(\text { Pa s) }\end{array}$ & $\begin{array}{l}\text { Model } 2 \eta \\
\quad(\text { Pa s) }\end{array}$ & $\begin{array}{l}\text { Model } 3 \eta \\
\quad(\text { Pa s) }\end{array}$ & $\begin{array}{l}\text { Model } 4 \eta \\
\quad \text { (Pa s) }\end{array}$ & $\begin{array}{l}\text { Model } 5 \eta \\
\quad(\text { Pa s) }\end{array}$ & $\begin{array}{c}\text { Model } 6 \eta \\
\quad(\mathrm{Pa} \mathrm{s})\end{array}$ \\
\hline Upper crust & 10.7 & 6.1 & 3.55 & 2740 & Elastic & Elastic & Elastic & Elastic & Elastic & Elastic \\
\hline Middle crust & 11 & 6.3 & 3.65 & 2780 & Elastic & Elastic & Elastic & Elastic & $1 \times 10^{19}$ & Elastic \\
\hline Lower crust & 11.4 & 6.6 & 3.7 & 2860 & $1 \times 10^{19}$ & $1 \times 10^{19}$ & $1 \times 10^{18}$ & $1 \times 10^{19}$ & $1 \times 10^{18}$ & $1 \times 10^{20}$ \\
\hline $\begin{array}{l}\text { Upper } \\
\text { mantle }\end{array}$ & 66.9 & 7.8 & 4.35 & 3220 & $3.2 \times 10^{20}$ & $1 \times 10^{20}$ & $1 \times 10^{20}$ & $1 \times 10^{19}$ & $1 \times 10^{21}$ & $3.2 \times 10^{19}$ \\
\hline
\end{tabular}

a Laske et al. (2013).

particular, the adopted rheology and the viscosity values for the lower crust and upper mantle are key parameters that control the velocity of the time-dependent stress release (Verdecchia \& Carena, 2015).

In Central Italy, some authors have inferred rheological features for the lithosphere by using high-precision leveling lines in the region struck by the $1915 M_{\mathrm{w}} 6.9$ Fucino earthquake (Amoruso et al., 2005) or aftershock strain maps, GPS, and leveling profile data, collected and modeled after the 1997 Colfiorito earthquake sequence (Aoudia et al., 2003; Riva et al., 2007). These studies suggest the presence below central Apennines of a thin upper crust (8-10 km) overlying a 10- to $12-\mathrm{km}$-thick low-viscosity $\left(10^{18}-10^{19} \mathrm{~Pa}\right.$ s) transition zone, on a 10 - to $15-\mathrm{km}$-thick viscous lower crust $\left(10^{18} \mathrm{~Pa} \mathrm{~s}\right)$, and finally the upper mantle ( $\left.10^{21} \mathrm{~Pa} \mathrm{~s}\right)$. All these works considered a Maxwell viscoelastic rheology.

In order to test the sensitivity of time-varying stress changes to viscoelastic properties, we compared several models proposed in previously cited papers and models proposed for similar tectonic environments (e.g., Basin and Range province; see Verdecchia \& Carena, 2015, and references therein). We thus modeled the cumulative $\triangle$ CFS due to the $1915 M_{\mathrm{w}} 6.9$ Fucino earthquake on the hypocentral location of the $2009 M_{\mathrm{w}}$ 6.3 L'Aquila earthquake (see location in Figure 1), just before its occurrence (viscoelastic relaxation lasted for 94 years), using six different Maxwell rheological models (Table 1). The time/stress curves in Figure S1 in the supporting information show similar behaviors for the last four models, where, as a result of the Maxwell viscoelastic model, stressing rate is decaying over time. Among these four models, Model 3 and Model 5, which both have a layer (lower crust) with viscosity of $10^{18} \mathrm{~Pa}$ s, show a rapid stress release for the first $\sim 15$ years. The first two models, instead, yield a constant, relatively slow rate over the whole postseismic time interval comprised between the two earthquakes. In addition, in the last four models, the difference between cumulative (coseismic plus postseismic) and coseismic $\triangle$ CFS highlights the importance of postseismic effects in earthquake triggering, if a sufficiently long time frame (from 10 to 100 years) is taken into account. Since Model 5 is constrained with data from the study region (Amoruso et al., 2005; Aoudia et al., 2003; Riva et al., 2007), we used it as the model of reference for our study, to calculate the $\triangle$ CFS evolution in Central Italy over the whole studied time window (1915-2017).

To evaluate the impact of the coseismic stress transfer and of the viscoelastic relaxation with intermediatesized normal earthquakes, such as the ones occurring in Central Italy, we modeled both the coseismic and the postseismic Coulomb stress changes due to synthetic sources (respectively with $M_{\mathrm{w}} 6.0,6.5$, and 7.0; see Figure 2), using Model 5 (see Table 1). The sizes of the rupture and of the coseismic slip are determined from empirical relationships (Wells \& Coppersmith, 1994).

Figure 2 shows the impact of the coseismic stress variation and of the viscoelastic relaxation in time and space; isolines represent the limits of the potential triggering effect as usually given in literature (Reasenberg \& Simpson, 1992; Stein, 1999). These sensitivity tests are plotted in terms of a hypothetical triggering threshold (stress change of about 0.2 bar) versus elapsed time in Figure $2 \mathrm{~d}$. These results suggest that the triggering effect due to coseismic Coulomb stress changes (1) is maximum along strike, except for the M6.0 source (the smaller the fault rupture, the more it mimics a point-like source), and (2) extends approximately for about one source length. Conversely, viscoelastic relaxation-driven triggering reaches quasiconstant values for the following:

1. about $10 \mathrm{~km}$ and 50 years after a $M_{\mathrm{w}} \sim 6.0$ earthquake;

2. $30 \mathrm{~km}$ and 100 years after a $M_{\mathrm{w}} \sim 6.5$;

3. $70 \mathrm{~km}$ and 150 years after a $M_{\mathrm{w}} \sim 7.0$. 

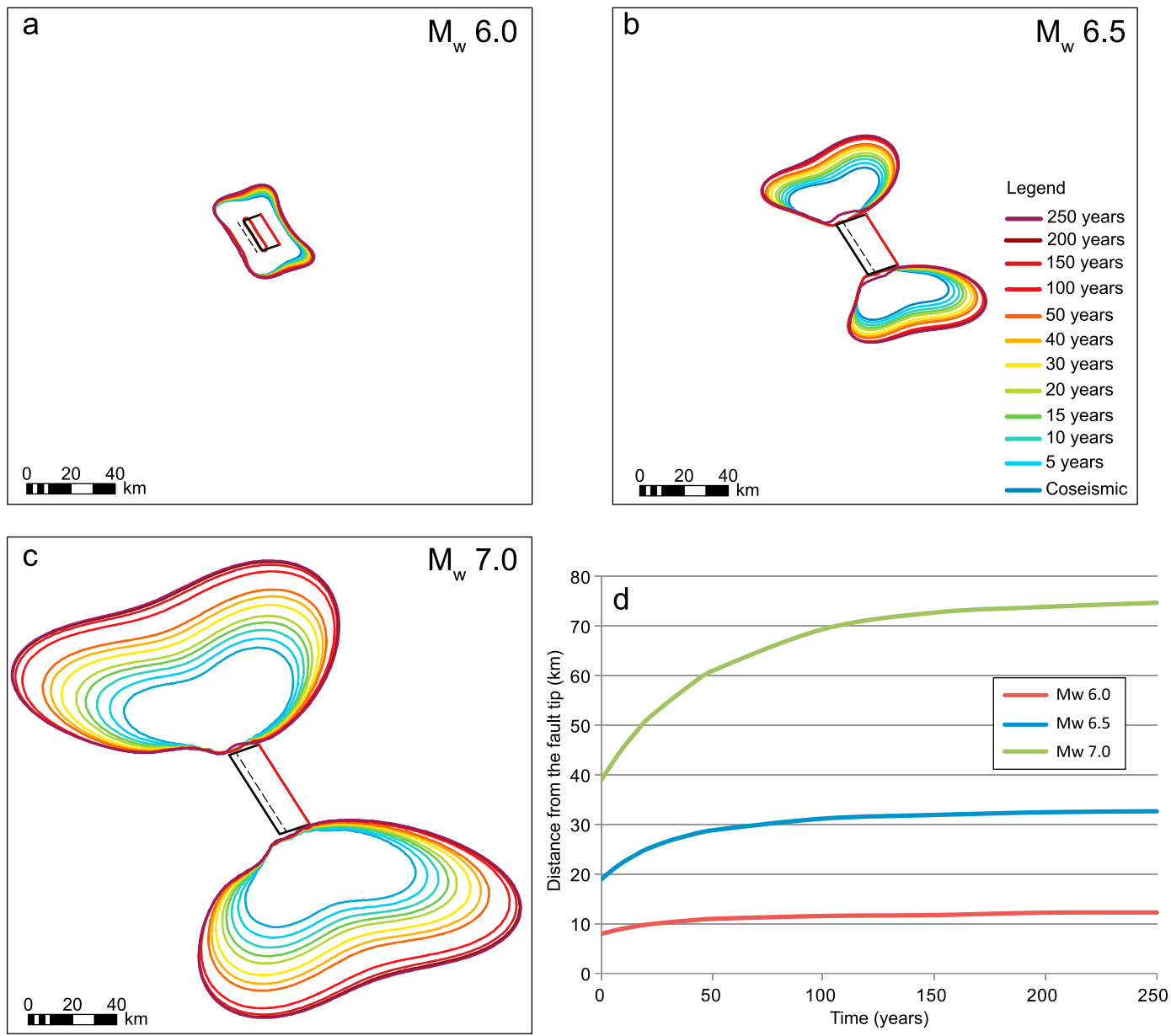

Figure 2. Spatiotemporal evolution of the 0.2 -bar isoline due to the cumulative (coseismic + postseismic) $\Delta$ CFS modeled for a (a) $M_{\mathrm{w}} 6$ normal-faulting earthquake, (b) $M_{\mathrm{w}} 6.5$ normal-faulting earthquake, and (c) $M_{\mathrm{w}} 7$ normal-faulting earthquake; and calculated at 10-km depth (dashed line). (d) Along-strike spatial evolution of the 0.2 -bar isoline for different earthquake scenarios. The red line represents the surface trace of the fault.

These theoretical computations, although based on simple assumptions of the geometry and the slip distribution, are a starting point for analyzing the whole historical catalogue in Central Italy and for modeling the most recent and well constrained events, as described in the following.

\section{Temporal and Spatial Analysis of Central Italy Seismicity}

As shown in Figure 1, the seismicity along central Apennines is well documented since 1300-1400 C, based mainly on historical data (Rovida et al., 2016). Using the time-distance relationship for potential triggering effects presented in the previous section, we searched for potential cascades of related earthquakes in historical records of seismicity from the central Apennines. We defined a potential short-term triggered cluster, as a sequence of events closely related both in space and time (i.e., earthquakes located at less than 10-20-km distance and occurring within less than $\approx 10$ years); the triggering mechanism, in this case, has to be coherent with the potential coseismic Coulomb stress changes. Conversely, long-term triggered events can be due, potentially, to viscoelastic stress transfer. Depending on the magnitude of the triggering event, postseismic $\Delta$ CFS may span over larger time spans ( $>100$ years) and larger distances (tens of kilometers), as already defined in the previous section. Figure 3 synthesizes the results of our analyses.

In more detail, Figure 3a displays the time and the position of the earthquakes along strike (parallel to the mountain chain), with a half width (distance perpendicular to the mountain chain) of $30 \mathrm{~km}$ (data from the catalogue CPTI15; Rovida et al., 2016). We used 983 earthquakes in total, with minimum magnitude equal 

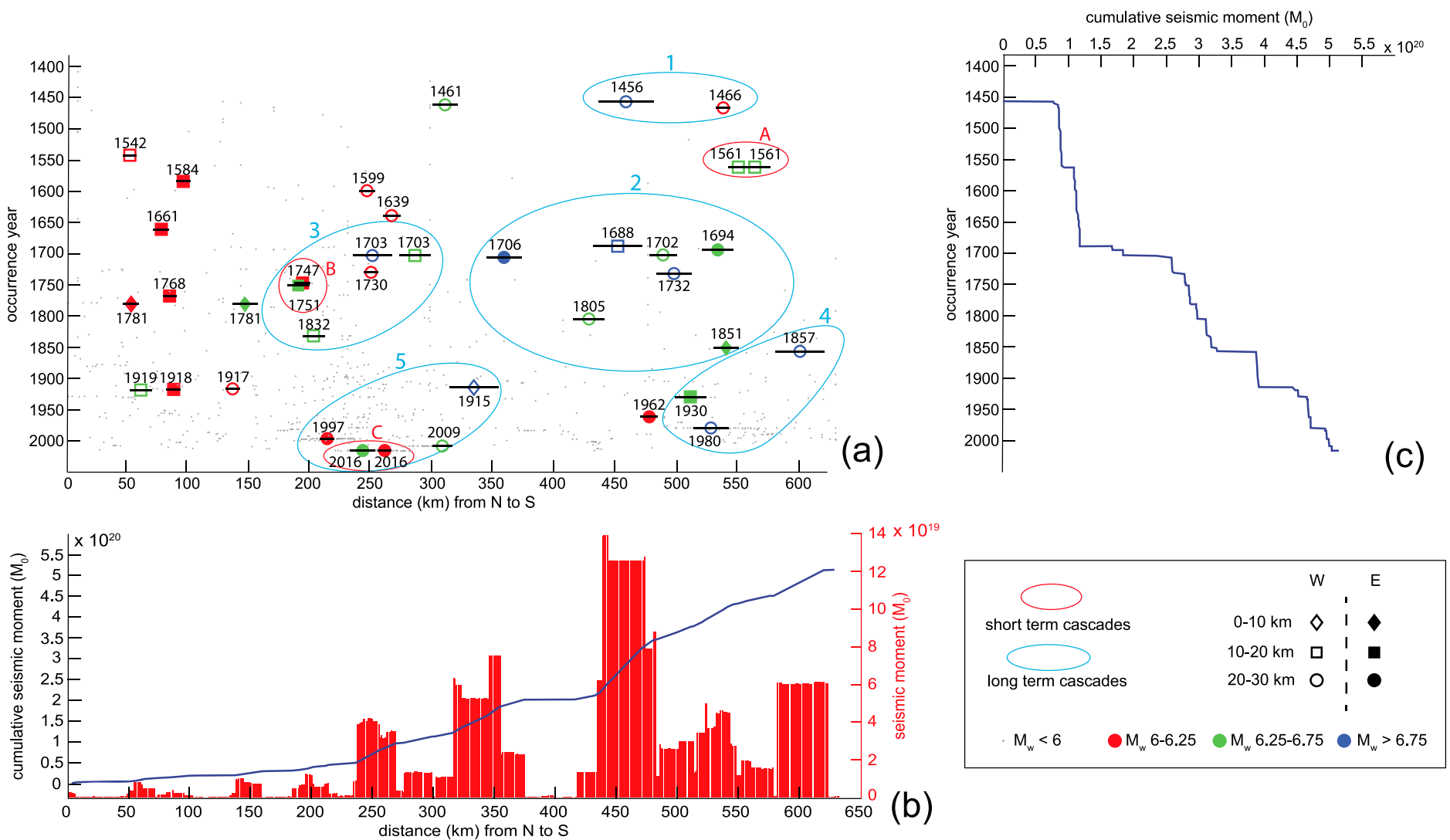

Figure 3. Seismicity distribution along the central Apennines: (a) earthquakes occurred along a section (location in Figure 1, earthquake data from CPTI15 catalogue, http://emidius.mi.ingv.it/CPTI15-BDMI15/) within a semidistance of $30 \mathrm{~km}$; the different colors represent the $M_{\mathrm{w}}$ values in four classes, the different symbols represent the distance from the section, the length of the horizontal lines is proportional to the earthquake magnitude (calculated from empirical scaling relationship), and the colored polygons represent the hypothesized short-term (in red) and long-term (in blue) triggered events. (b) Seismic moment versus distance along the section, from north to south. (c) Cumulative seismic moment versus year of occurrence.

to 3.2, of which 71 are of magnitude $M_{\mathrm{w}} \geq 5.5$, starting from 1400 onward. The colored lines envelope the possible earthquake cascades (red for short term triggering, blue for long term, see also Table 2), defined by using the above-defined thresholds. We calculated distances among different earthquakes by taking into account some finite rupture size of the fault (empirical relationships by Wells and Coppersmith, 1994; see the horizontal lines in Figure 3a) as the diameter of a circle with the center on the epicenter. The distance computation does not consider the earthquake depth as it is not relevant for our purposes (most of the seismicity is confined in the first $20 \mathrm{~km}$ ) and is also not reliably determined for historical seismicity data. The figure suggests the occurrence of three different short-term cascades and five different longterm cascades. In particular, we identified as short-term cascades the pair of events that occurred in 1561 in the southern sector (Vallo di Diano, $M_{\mathrm{w}} 6.3$ in July and $M_{\mathrm{w}} 6.7$ in August), two events in the middle of $\mathrm{XVI}$ sec. in the central sector (Appennino Umbro-Marchigiano, $M_{\mathrm{w}} 6.1$ in April 1747 and $M_{\mathrm{w}} 6.4$ in July 1751), and the three main events of the 2016-2017 Central Italy seismic sequence (24 August, $M_{\mathrm{w}} 6.0 ; 26$ October, $M_{\mathrm{w}} 5.9$; and 30 October 2016, $M_{\mathrm{w}}$ 6.5). Conversely, considering the possible long-term triggering, we identified five different earthquake cascades, described hereafter from the oldest to the youngest. The oldest one is characterized by two events in the middle of XIII sec.: the $1456 M_{\mathrm{w}} 7.2$ Matese earthquake and the $1466 M_{w} 6.0$ Irpinia-Basilicata earthquake. The second identified cascade is longer and characterized by seven major earthquakes, located in the central-southern sector from 1688 to 1805 . Within this sequence, three events had $M_{\mathrm{w}}$ larger than 6.7: the first one occurred in 1688 in Sannio region $\left(M_{\mathrm{w}} 7.1\right)$, followed by the 1706 Maiella $\left(M_{\mathrm{w}} 6.8\right)$ and 1732 Irpinia $\left(M_{\mathrm{w}}\right.$ 6.75) earthquakes. The third cascade occurred in the central Apennines and started in 1703, with two main events of $M_{\mathrm{w}} 6.9$ (Valnerina area) and $M_{\mathrm{w}} 6.7$ (L'Aquila), including the short-term cascade B (1747 and 1751), and finished with the $1832 M_{w} 6.4$ Valle Umbra earthquake. 
Table 2

Identified Earthquake Cascades

\begin{tabular}{lccccc}
\hline Year & Longitude & Latitude & $M_{\mathrm{w}}$ & Cascade ID & Cascade type $^{\mathrm{a}}$ \\
\hline $1561(1)$ & 15.389 & 40.650 & 6.3 & $\mathrm{~A}$ & $\mathrm{ST}$ \\
$1561(2)$ & 15.505 & 40.563 & 6.7 & $\mathrm{~A}$ & $\mathrm{ST}$ \\
1747 & 12.769 & 43.204 & 6.1 & $\mathrm{~B}$ & $\mathrm{ST}$ \\
1751 & 12.769 & 43.225 & 6.4 & $\mathrm{~B}$ & $\mathrm{ST}$ \\
$2016(1)$ & 13.234 & 42.698 & 6.0 & $\mathrm{C}$ & $\mathrm{ST}$ \\
$2016(2)$ & 13.111 & 42.832 & 6.5 & $\mathrm{C}$ & $\mathrm{ST}$ \\
1456 & 14.711 & 41.302 & 7.2 & 1 & LT \\
1466 & 15.334 & 40.765 & 6.0 & 1 & LT \\
1688 & 14.561 & 41.283 & 7.1 & 2 & LT \\
1694 & 15.406 & 40.862 & 6.7 & 2 & LT \\
1702 & 14.989 & 41.120 & 6.6 & 2 & LT \\
1706 & 14.080 & 42.076 & 6.8 & 2 & LT \\
1732 & 15.059 & 41.064 & 6.8 & 2 & LT \\
1805 & 14.474 & 41.500 & 6.7 & 2 & LT \\
1851 & 15.669 & 40.960 & 6.5 & 2 & LT \\
$1703(1)$ & 13.071 & 42.708 & 6.9 & 3 & LT \\
$1703(2)$ & 13.292 & 42.434 & 6.7 & 3 & LT \\
1730 & 13.120 & 42.753 & 6.0 & 3 & LT \\
1747 & 12.769 & 43.204 & 6.1 & 3 & LT \\
1751 & 12.739 & 43.225 & 6.4 & 3 & LT \\
1832 & 12.605 & 42.980 & 6.4 & 3 & LT \\
1857 & 15.842 & 40.352 & 7.1 & 4 & LT \\
1930 & 15.318 & 41.068 & 6.7 & 4 & LT \\
1980 & 15.283 & 40.842 & 6.8 & 4 & LT \\
1915 & 13.530 & 42.014 & 6.9 & 5 & LT \\
1997 & 12.853 & 43.014 & 6.0 & 5 & LT \\
2009 & 13.510 & 42.309 & 6.3 & 5 & LT \\
2016 & 13.234 & 42.698 & 6.0 & 5 & LT \\
2016 & 13.111 & 42.832 & 6.5 & 5 & LT \\
\hline $9.5 T=5 h$ & & & 5 &
\end{tabular}

${ }^{\mathrm{a}} \mathrm{ST}=$ short-term, LT = long-term.
The 1703 events fall slightly outside our predefined distance threshold for short-term cascades. Because of the magnitude of these events and mostly because of the uncertainties connected with their location, we do not rule out the possibility that these two large events that occurred in 1703 may be related in terms of coseismic $\triangle$ CFS. The fourth cascade is located in the southern sector and characterized by three main earthquakes, which started in 1857 (Basilicata, $M_{\mathrm{w}}$ 7.1) and ended with the $1980 M_{\mathrm{w}} 6.8$ Irpinia earthquake. Finally, the last identified long-term cascade started in 1915 with the $M_{\mathrm{w}} 7.1$ Fucino earthquake, continued with the 1997 Colfiorito and 2009 L'Aquila sequences, extended to the 2016-2017 Central Italy sequence and is potentially still ongoing.

Figure 3 also represents the seismic moment plotted both along the strike of the chain (Figure $3 b$, section in Figure 1) and versus time (Figure $3 \mathrm{c}$ ). The total value of released seismic moment in the last $\sim 600$ years in this region is $\sim 5.1 \times 10^{20} \mathrm{~N} \mathrm{~m}$, corresponding to an energy release of $\sim 60,000$ TJ. Figure $3 \mathrm{~b}$ shows a clear increase of the moment release for the portion between 250 and $650 \mathrm{~km}$, with a part corresponding to the Matese-Irpinia area (350-450 km) displaying a flatter curve that could suggest a seismic gap in the time window covered by the earthquake catalogue. When moment release is plotted versus time (Figure $3 \mathrm{c}$ ), the trend shows two main bursts of seismic moment release around $1450 \mathrm{CE}$ and $1700 \mathrm{CE}$ and an additional smaller burst around $1850 \mathrm{CE}$ and $1900 \mathrm{CE}$. The two main bursts correspond to a total seismic moment of about $1 \times 10^{20}$ and $1.5 \times 10^{20} \mathrm{~N} \mathrm{~m}$. Here we suggest that both the spatial (Figure $3 \mathrm{~b}$ ) and temporal (Figure $3 \mathrm{c}$ ) analyses of the seismicity should be considered together in order to better understand the relationship among moderate-to-strong earthquakes along the Apennines.

\subsection{Stress Changes After the 1915 Fucino Earthquake}

Precise locations and slip distributions of earthquakes have a large impact on Coulomb stress changes calculations, and they depend on the availability of seismological and geodetic data. Because in Central Italy this information is available only for recent events, we focused our attention on the last long-term earthquake sequence (cascade n.5 in Figure 3 and Table 2) initiated with the 1915 Fucino earthquake, the most catastrophic instrumentally recorded event that hit the area. For this first earthquake we used the slip model from Paolucci et al. (2016; Figure 4a, Table 3), which in turn is based on the variable slip planar model of Ward and Valensise (1989) calculated using geodetic leveling data from the Fucino plain. The three 1997 Colfiorito earthquakes are modeled using the results form Hernandez et al. (2004; Figure S3a, Table 3), which are based on a joint inversion of GPS, DInSAR, and strong motion data. The slip distribution on the Paganica fault, responsible for the 2009 L'Aquila earthquake (Figure S3b, Table 3), was determined by Gallovič et al. (2015) inverting strong motion and GPS data. In addition to the mainshock, we also considered the slip distribution on the southern section of the Mount Gorzano fault (Cheloni et al., 2014), activated during a sequence of five $M>4.5$ aftershocks in 2009. Finally, we modeled the 2016 three main events using the results from the strong motion data inversion of Tinti et al. (2016; Amatrice earthquake; Figure S4a, Table 3) and Chiaraluce et al. (2017; Visso and Norcia earthquakes; Figure S4a and S4b, Table 3). Below we describe the results of the Coulomb stress modeling with emphasis on the stress changes accumulated at the hypocenter of the studied events.

The coseismic effect of the 1915 Fucino earthquake transferred $\sim 0.28$ bar of positive $\Delta$ CFS at the hypocenter of the 2009 earthquake (Figures $4 \mathrm{a}$ and 5a), while it had very small or no effect at the locations of the other events studied (Figures $4 a$ and 5a). The 1997 Colfiorito sequence, modeled as three $M_{\mathrm{w}} \geq 5.6$ events, had no impact on the 2009 L'Aquila earthquake due to the large distance between the events, but it increased the stress at the nucleation location of the 26 October $2016 M_{\mathrm{w}} 5.9$ Visso earthquake and of the 30 October $2016 M_{\mathrm{w}} 6.5$ Norcia earthquake (Figure 5a). 

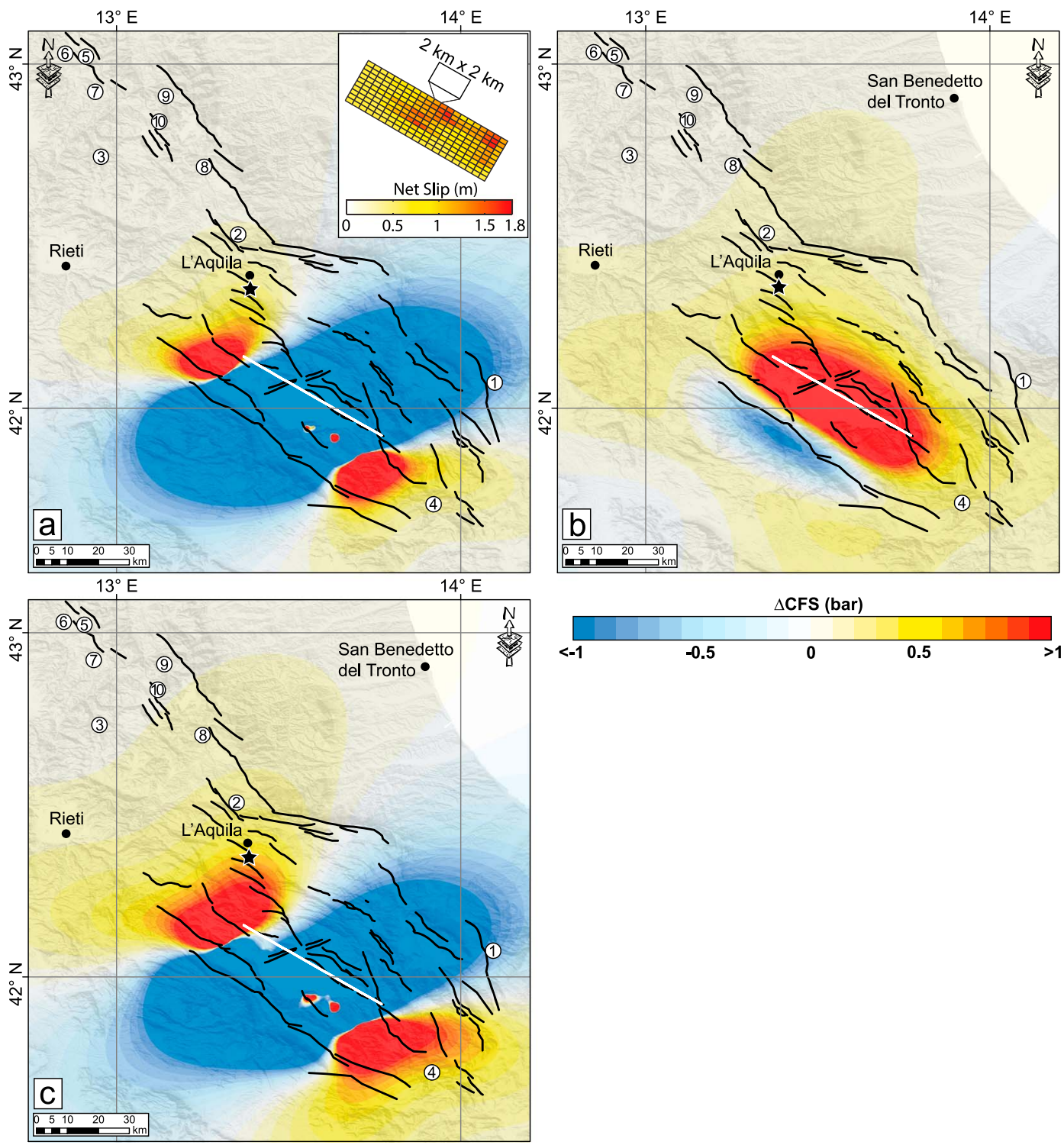

Figure 4. $\triangle$ CFS due to the 1915 Fucino earthquake resolved on the 2009 L'Aquila earthquake (black star: depth of $8.6 \mathrm{~km}$ by Chiaraluce et al., 2001; kinematics by Scognamiglio et al., 2010): (a) Coseismic, (b) 94 years of postseismic, and (c) cumulative (coseismic + postseismic). The white lines represent the surface trace of the modeled source fault (slip model from Paolucci et al., 2016, in the inset), and the white circles are the post-1915 largest earthquakes numbered in chronological order: (1) 26 September 1933, $M=5.6$; (2) 5 September 1950, $M=5.7$; (3) 19 September 1979, $M_{\mathrm{w}}=5.8$; (4) 7 May 1984, $M=5.9 ;$ (5) 26 September 1997, $M_{\mathrm{w}}=5.7$; (6) 26 September 1997, $M_{\mathrm{w}}=6.0$; (7) 14 October 1997, $M_{\mathrm{w}}$ 5.6; (9) 24 August 2016, $M_{\mathrm{w}}=6.0 ;$ (9) 26 October 2016, $M_{\mathrm{w}}=5.9$; and (10) 30 October 2016, $M_{\mathrm{w}} 6.5$.

In Figures 4 and 5a, we show that the effect of time-dependent postseismic stresses has more than doubled the initial coseismic $\Delta C F S$ at the hypocenter of the $2009 M_{\mathrm{w}} 6.3$ L'Aquila earthquake. Conversely, this latter devastating event, with the contribution of moderate aftershocks on the southern section of the $M$. Gorzano fault, has imparted a very small effect $(<0.1$ bar) on the area struck by the 2016 Central Italy earthquake sequence, with very small effects due to 7 years of postseismic relaxation. When we combine the stress changes due to the 1915, 1997, and 2009 events (Figure $5 b$ and $6 a$ ), the cumulative $\Delta C F S$ reaches values of 0.2-0.3 bar. In particular, at the hypocenter of the 24 August $2016 M_{\mathrm{w}} 6.0$ Amatrice earthquake (the first event of the 2016 sequence), we estimated $\sim 0.2$ bar of cumulative $\Delta$ CFS (Figures $5 \mathrm{~b}$ and $6 \mathrm{a}$ ) due to the summation of all the previous events, as modeled in this study. The first earthquake of the 2016 sequence further increased the stress at the location of the subsequent 26 October $2016 M_{\mathrm{w}} 5.9$ Visso earthquake 
Table 3

Rupture Parameters of the Modeled Earthquakes

\begin{tabular}{|c|c|c|c|c|c|}
\hline Date & Location & Depth $(\mathrm{km})$ & $M_{\mathrm{w}}$ & Strike/dip/rake (degrees) & Slip model \\
\hline 13/01/1915 & Fucino & $?$ & 6.9 & $128 / 53 /-100^{d}$ & Paolucci et al. (2016) \\
\hline 26/09/1997 & Colfiorito & $4.0^{\mathrm{a}}$ & $5.7^{\mathrm{a}}$ & $152 / 46 /-90^{a}$ & Hernandez et al. (2004) \\
\hline 26/09/1997 & Colfiorito & $5.1^{\mathrm{a}}$ & $6.0^{\mathrm{a}}$ & $144 / 42 /-90^{\mathrm{a}}$ & Hernandez et al. (2004) \\
\hline $14 / 10 / 1997$ & Colfiorito & $5.8^{\mathrm{a}}$ & $5.6^{\mathrm{a}}$ & $135 / 45 /-90^{a}$ & Hernandez et al. (2004) \\
\hline 06/04/2009 & L'Aquila & $8.6^{b}$ & $6.3^{b}$ & $139 / 48 /-87^{e}$ & $\begin{array}{l}\text { Gallovič et al. (2015) } \\
\text { Cheloni et al. (2014) }\end{array}$ \\
\hline 24/08/2016 & Amatrice & $7.9^{c}$ & $6.0^{c}$ & $155 / 49 /-89^{c}$ & Tinti et al. (2016) \\
\hline $26 / 10 / 2016$ & Visso & $3.4^{c}$ & $5.9^{c}$ & $159 / 47 /-93^{c}$ & Chiaraluce et al. (2017) \\
\hline $30 / 10 / 2016$ & Norcia & $7.3^{c}$ & $6.5^{c}$ & $151 / 47 /-93^{c}$ & Chiaraluce et al. (2017) \\
\hline
\end{tabular}

${ }^{\mathrm{a}}$ Hernandez et al. (2004). ${ }^{\mathrm{b}}$ Chiaraluce et al. (2011). ${ }^{\mathrm{c}}$ Chiaraluce et al. (2017). ${ }^{\mathrm{d}}$ Paolucci et al. (2016). ${ }^{\mathrm{e}}$ Scognamiglio et al. (2010). ${ }^{\mathrm{f}}$ Slip distribution on the Campotosto fault due to aftershocks sequence.

(Figures $5 \mathrm{~b}$ and $6 \mathrm{~b}$ ); the combination with previous events produced a positive $\triangle$ CFS of $\sim 2.4$ bars (Figures $5 \mathrm{~b}$ and $6 \mathrm{c}$ ) at the hypocenter of the largest event of the 2016 sequence, the 30 October $2016 M_{\mathrm{w}} 6.5$ Norcia earthquake.

Note that if we calculate the present-day cumulative $\Delta$ CFS due to all the $M>6$ earthquakes since 1915, modeled with a special focus on the $M$. Gorzano fault, where four $M_{\mathrm{w}} \geq 5$ aftershocks occurred in January 2017 (Figure 7), we find that a $\triangle$ CFS larger than 1 bar has been accumulated on a large section of the fault ( 15km length). The main contributions are due to the 2009 and 2016 Central Italy earthquakes.
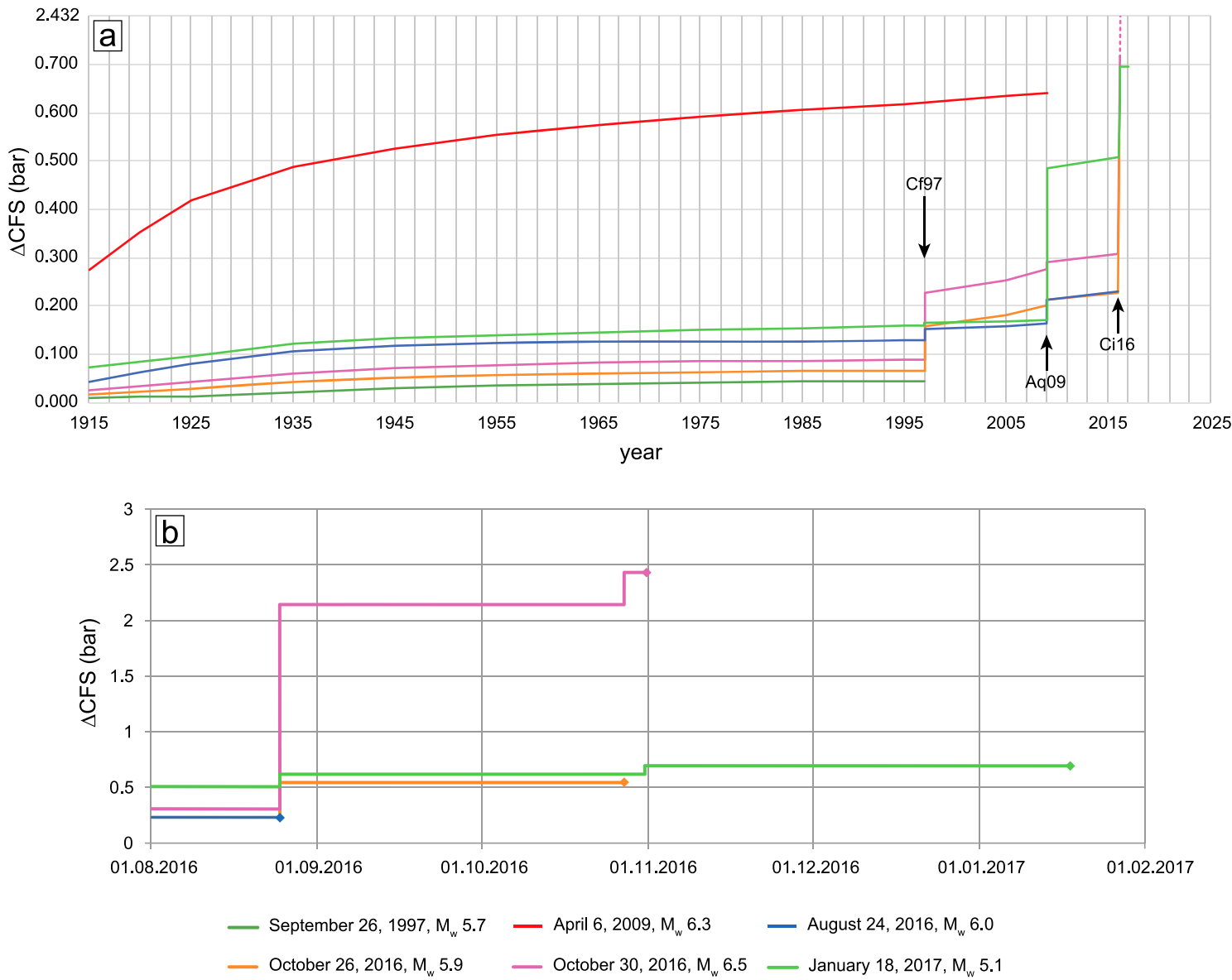

Figure 5. (a) Cumulative (coseismic + postseismic) $\triangle C F S$ evolution resolved at the hypocenter of the five modeled events following the $1915 M_{\mathrm{w}} 6.9$ Fucino earthquake plus the first of the 18 January $2017 M_{\mathrm{w}}>5$ aftershocks of the 2016 sequence. (b) Same as (a) but focused on the period between 1 August 2016 and 1 February 2017. Cf97 is the 1997 Colfiorito sequence, Aq09 is the 2009 L'Aquila earthquake, and Ci16 is the 2016 Central Italy sequence. 

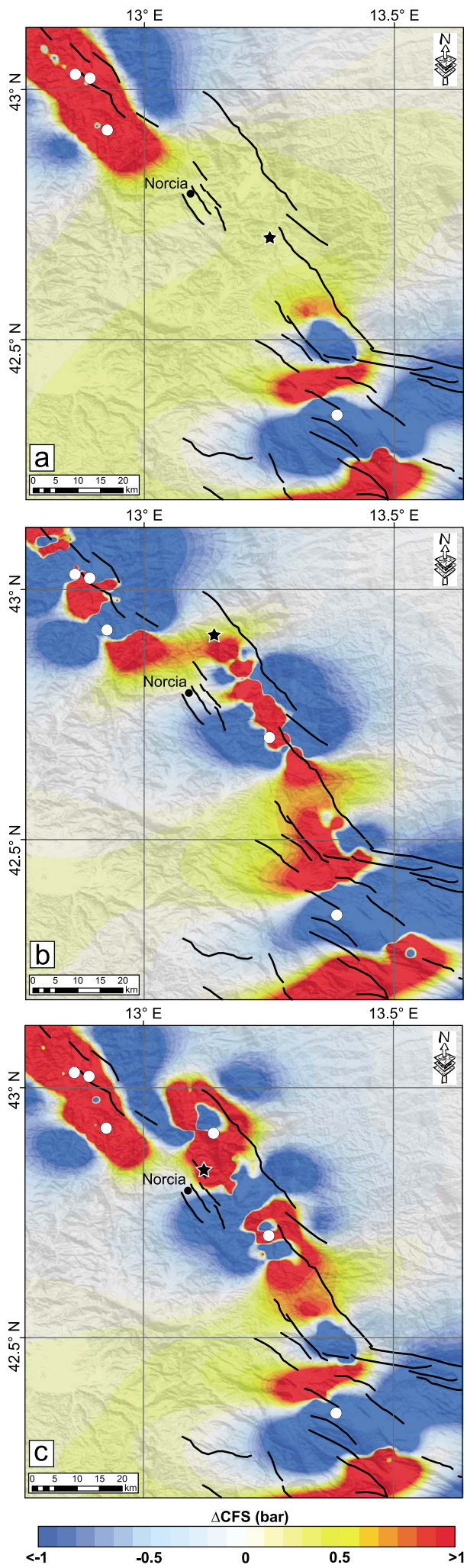

Figure 6. Cumulative (coseismic + postseismic) $\Delta$ CFS due to all modeled events (white circles) prior the occurrence of and resolved at the hypocenter of (a) the 24 August $2016 M_{\mathrm{w}}=6.0$ earthquake (black star), (b) the 26 October $2016 M_{\mathrm{w}} 5.9$ earthquake (black star), and (c) the 30 October $2016 M_{\mathrm{w}}$ 6.5 earthquake (black star).

\section{Discussion}

A wide range of processes have been invoked to explain the interaction between faults in a fault system such as elastic stress transfer (coseismic), dynamic stress changes (stress induced by the passage of seismic waves), and fluid migration through fault zones (see Freed, 2005; DeVries et al., 2016 , for in-depth discussion). However, in spite of the fact that our understanding of earthquakes interaction has considerably evolved since the 1990s, most seismic hazard studies are still based on Poissonian hypotheses for earthquake occurrences; even for regions where faults are considered from a sophisticated time-dependent seismic hazard perspective (e.g., for Central Italy; Pace et al., 2006), earthquake rupture forecasts are still modeled without considering the interaction of neighboring fault segments. The need to evolve toward fault system based analyses was already identified by Scholz and Gupta (2000). The question raised concerning the likelihood that a future earthquake remains confined to a single fault, or that it may jump to adjacent faults/segments thus resulting in a larger earthquake, faces major obstacles: a detailed knowledge of (i) the 3D geometry of a fault system, (ii) the time histories of past earthquakes, and (iii) reliable approximations of the complexities of their rupture process. In addition, benchmark studies performed in fast-deforming areas dominated by strike-slip faults (e.g., in California and Turkey; Field et al., 2015; Gülerce et al., 2017) are not suitable in slowly deforming regions with normal faulting, like Central Italy. Recently, some test studies considered faults not as isolated features but as existing within a population of faults that may interact through their stress fields (e.g., Pace et al., 2014; Visini \& Pace, 2014), and new methodological approaches exist (e.g., Chartier et al., 2017). Mildon et al. (2017) made a further step in that direction by modeling Coulomb stress transfer prior to the Central Italy 2016 seismic sequence on strike-variable fault geometries. The resulting buildup of stress generated stress heterogeneities that correlate with the limits of the 2016 mainshock ruptures. In their modeling approach, however, no viscoelastic processes were accounted for, the timing of earthquake occurrence being driven by the long-term loading rates at the base of the faults, modulated by static Coulomb stress transfer. Our study tries to overcome these known limitations at least concerning viscoelasticity and the source characterization of earthquakes from the previous century.

\subsection{Earthquake Clustering in the Apennines}

Using some simple rules and analyzing the space-time distribution of Central Italy seismicity (CPTI15 catalogue; Rovida et al., 2016), we defined some potential short-term and long-term earthquake cascades along the Apennines. The short-term cascades can be explained only by the coseismic Coulomb stress changes, while the long-term cascades are attributed to viscoelastic processes. We identified five different possible long-term earthquake cascades, of which the most recent is still potentially ongoing.

Other papers have previously discussed the possibility of space-time clustering of earthquakes, ascribing the process to dynamic or static stress propagation processes (e.g., King \& Cocco, 2001; Stein et al., 1992) or to pore pressure diffusion over a fault system (e.g., Antonioli et al., 2005). Chiarabba et al. (2011) identified in Central Apennines two series of devastating earthquakes in which one is inferred to have triggered a cascade of subsequent events (earthquake storms). The authors suggest a periodicity 

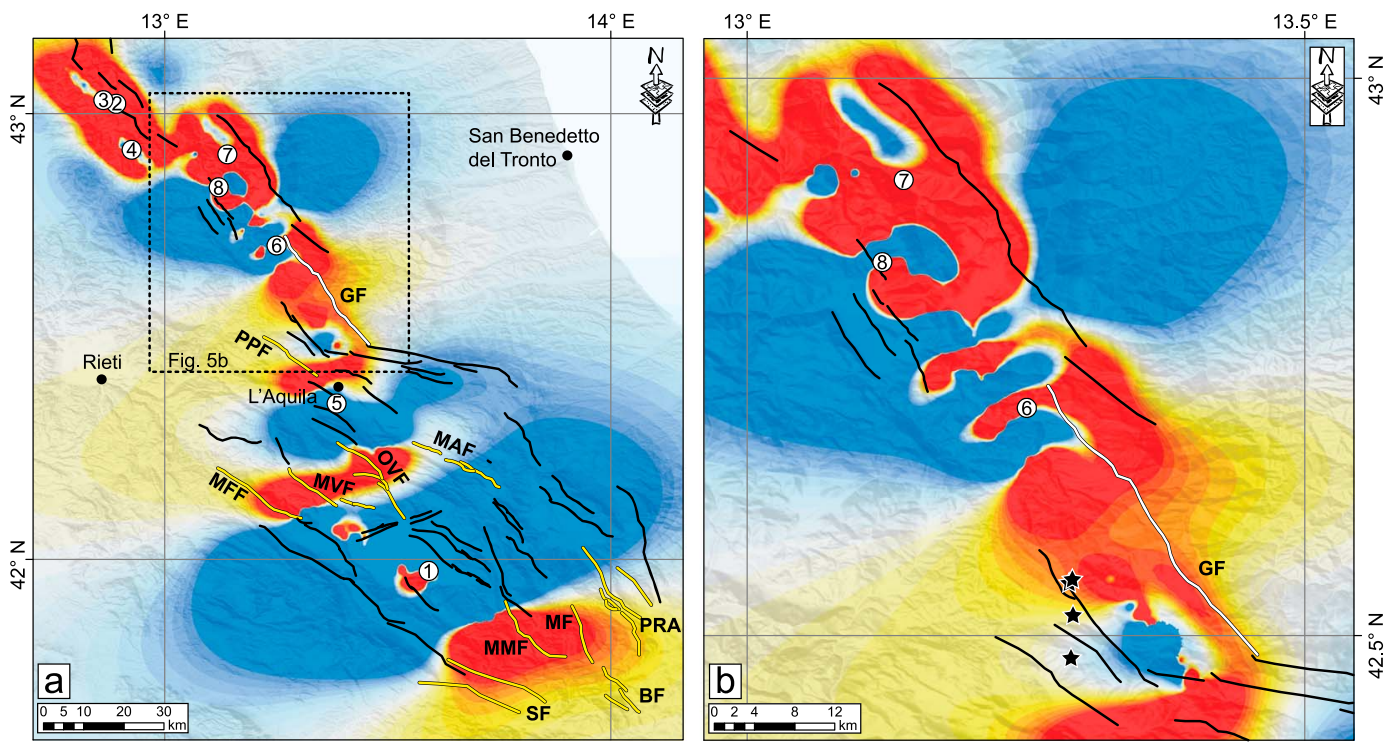

$\triangle$ CFS (bar)

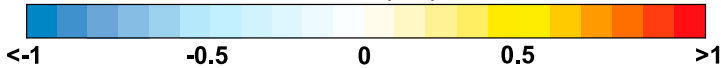

Figure 7. (a) Regional and (b) zoomed view of the present-day (103 years) cumulative (coseismic + postseismic) $\Delta$ CFS from all the studied events (white circles), calculated on the kinematics of the Gorzano fault (strike 155, dip 50, rake -90 ; white line) considering a depth of $8 \mathrm{~km}$. Yellow lines are the faults brought close to failure discussed in section 4.2. BF, Barrea Fault; GF, Gorzano Fault; MAF, Middle Aterno Valley Fault; MF, Montagnola Fault; MFF, M. Faito Fault; MMF, M. Marsicano Fault; MVF, Magnola-Velino Fault; OVF, Ovindoli-Campo Felice Fault; PPF, Pizzoli-Pettino Fault; PRA, Pizzalto-RotellaAremogna Fault system; SF, Sora Fault. Source earthquakes numbered in chronological order: (1) 13 January 1915, $M_{\mathrm{w}}=6.9$; (2) 26 September 1997, $M_{\mathrm{w}}=5.7$; (3) 26 September 1997, $M_{\mathrm{w}}=6.0$; (4) 14 October 1997, $M_{\mathrm{w}}=5.6$; (5) 6 April 2009, $M_{\mathrm{w}}=6.3$; (6) 24 August 2016, $M_{\mathrm{w}}=6.0$; (7) 26 October 2016, $M_{\mathrm{w}}=5.9$; and (8) 30 October 2016, $M_{\mathrm{w}} 6.5$. Black stars are the 18 January $2017 M_{\mathrm{w}}>5$ aftershock of the 2016 Central Italy sequence.

of roughly 300 years and a process of deep fluids migration in the brittle upper crust as the driving mechanism.

Our results, looking into the space-time distribution of earthquakes with the physical constraints of the cumulative $\triangle$ CFS modeling given in section 2.2, suggest that different clustering processes may exist, potentially controlled by coseismic (short-term) stress changes and postseismic (long-term) viscoelastic relaxation (red and blue lines in Figure 3). We do not identify a periodicity for these clusters, bearing in mind that the system is probably more complex and that we have not considered several critical epistemic and aleatoric uncertainties. Because no precise data concerning location and slip distribution are available for the oldest events, in this work we only explore in detail the sequence of events that occurred in Central Italy between 1915 and 2017.

\subsection{The Last Century of Earthquake Interactions in Central Italy}

Our results show the contribution of viscoelastic stress transfer in the secular process of earthquake cascades. We suggest that the $1915 M_{\mathrm{w}} 6.9$ Fucino earthquake acted as a trigger for a secular and still ongoing earthquake long-term cascade. In particular, it contributed mostly to the triggering of the 2009 L'Aquila earthquake, with a cumulative (coseismic plus postseismic, see Figure $4 \mathrm{c}$ and red curve in Figure $5 a$ ) $\Delta$ CFS of $\sim 0.6$ bar. Note that a similar stress change after about 80 years reaches also the southern sectors of Fucino area, where the Barrea $M_{\mathrm{w}} 5.91984$ earthquake occurred (Pace et al., 2002); this event has not been modeled in this study because it is too small and too far from the 2016-2017 sequence location.

Considering the secular tectonic loading, Mildon et al. (2017) have estimated $\sim 0.003$ and $\sim 0.005$ bar/year of mean loading rate respectively for the Vettore and Gorzano fault. If we assume that these two faults and the Paganica fault have similar slip rate values (Valentini et al., 2017), then the interseismic $\Delta C F S$ calculated over 94 years (from 1915 to 2009) for the Paganica fault is $\sim 0.37$ bar, a value very similar to the one calculated for 
94 years of postseismic $\triangle$ CFS. Thus, the total $\Delta C F S$ (coseismic + postseismic + interseismic) accumulated on the hypocenter of the $2009 M_{\mathrm{w}} 6.3$ L'Aquila earthquake is $\sim 1$ bar. These values suggest that (i) postseismic and interseismic $\triangle C F S$ could be equally important in tectonically active regions characterized by relative low loading rates ( $<0.01 \mathrm{bar} / \mathrm{year}$ ) and (ii) a total $\triangle \mathrm{CFS}$ of $\sim 1$ bar is small when compared to average earthquake stress drops ( 35 bars) expected for moderate-to-large earthquakes (Hanks, 1977; Scholz, 2002), suggesting that the Paganica fault, before the $1915 M_{\mathrm{w}} 6.9$ Fucino earthquake, was already likely close to failure. Such a time delay between large earthquakes due to postseismic $\Delta C F S$ processes has already been invoked in Mongolia by Chéry et al. (2001) and in western U.S. by Verdecchia and Carena (2016).

In the area where the 2016-2017 Central Italy sequence occurred, the combination of the 1915, 1997, and 2009 earthquakes have produced a wide region of positive but moderate magnitude cumulative $\Delta C F S$ $\left(\geq 0.2\right.$ bar, in Figure $5 a$ the stress changes resolved on the first earthquake of 24 August $M_{w} 6.0$ ); note in Figure 7 that the participation of these events in the stress histories of the most recent earthquakes is comparable and that the first rupture to occur was not the one with the highest stress changes forecasted by this modeling (green and pink curves, representing the January 2017 and 30 October 2016 hypocenters above the blue curve of 24 August). Then, we argue that they possibly facilitated the occurrence of the August 2016 event that was already likely close to failure. Finally, the most significant jump in stress changes is given by the Amatrice earthquake on all the subsequent events, with a contribution of about 2 bars for the major $M_{\mathrm{w}} 6.5$ event. Note that resolved on the kinematics of Gorzano fault (Figure 6), a large patch of the structure is still subjected to positive stress, not significantly reduced by the occurrences of the aftershocks of January 2017. Our results clearly show (Figures $6 b$ and $6 c$ ) how the three events of the 2016-2017 sequence are strictly correlated in terms of coseismic $\triangle$ CFS to the main ones.

\subsection{Present State of Stress on the Gorzano Fault and on Other Active Faults in Central Italy}

In regions of diffuse deformation, characterized by a complex network of active faults, Coulomb stress changes due to one or more events could modify the state of stress of several surrounding faults. Nevertheless, the total amount of stress on a fault not only is the result of coseismic and postseismic $\Delta C F S$ due to past earthquakes, but mostly comes from interseismic $\triangle$ CFS accumulated over the entire seismic cycle $(\sim 1,000$ years for faults in the Apennines). We showed in the previous section that postseismic $\Delta$ CFS may be comparable in magnitude to interseimic $\Delta C F S$ in the $~ 100$-year time span following a large earthquake. Over the entire seismic cycle, however, interseismic $\triangle$ CFS controls the occurrence of earthquakes. In this section we discuss the coseismic plus postseismic $\Delta$ CFS accumulated by several faults, which, according to paleoseismological data, may be at the end of their seismic cycle.

According to the results of this study, the Gorzano fault has been largely loaded by the sequence of moderate-to-large events modeled here (Figure 7). In particular, the combination of the cumulative $\Delta C F S$ produced by the 2009 L'Aquila and the 2016-2017 Central Italy sequences has created a large region of positive $\triangle$ CFS along the central and southern parts of the Gorzano fault for a total length of $\sim 25 \mathrm{~km}$ (Figures $7 \mathrm{~b}$ and S2).

Although hundreds of aftershocks related to the 2016-2017 sequence (four $M_{w} \sim 5.5$ events; Chiaraluce et al., 2017) occurred in the study region, the central and southern sections of the Gorzano fault have not experienced any strong $(M \geq 6)$ earthquakes in the recent past. In fact, the only historical event associated with this fault is the 1639 earthquake $\left(M_{\mathrm{a}}=6.3\right)$, which, as with the $2016 M_{\mathrm{w}} 6.0$ Amatrice earthquake, possibly ruptured only the northern section of the fault (Boncio et al., 2004). Therefore, considering the large ( $>2$ bars) $\Delta$ CFS accumulated on this fault in the last 103 years, we believe that the Gorzano fault may have not released all its seismic potential.

Several other active faults in our study region seem to have accumulated positive cumulative $\Delta C F S$ in the last 103 years (yellow segments in Figure 7a). The Pizzoli-Pettino fault has been loaded by the 2009 L'Aquila earthquake in particular in its southern section ( $\triangle$ CFS $>1$ bar). This fault, however, was probably responsible for a relatively recent $M_{\mathrm{w}} 6.7$ earthquake on 2 February 1703 that struck this region (Pace et al., 2006).

South of L'Aquila, a series of four faults have been affected by both the 2009 and the 1915 Fucino earthquakes. Eastward, the northern section of the Middle Aterno fault system has been brought closer to failure and, according to a paleoseismological study from Falcucci et al. (2011), has not produced any surfacerupturing event for at least the last $\approx 2,100$ years. The same authors defined a maximum magnitude of 6.6- 
6.8 expected from a complete rupture of this fault system. To the west, the Ovindoli-Campo Felice fault and the Magnola-Velino fault have both accumulated large values ( $>1$ bar) of $\Delta$ CFS and are also two of the most studied faults in the region. $A M_{\mathrm{w}} 5.6$ earthquake in 1315 has been related to the Ovindoli-Campo Felice fault (Valentini et al., 2017), and a paleoseismological study from Pantosti et al. (1996) shows evidence of at least three surface-rupturing events in the last $~ 7,500$ years, with the most recent event dated 1330-890 CE. The $1904 M_{\mathrm{w}} 5.7$ Marsica earthquake has been associated by Pace et al. (2006) to the Magnola-Velino fault, and the last surface-rupturing event was dated $1300 \pm 400$ years B.P. by Schlagenhauf et al. (2011). Both these faults are capable of $M_{\mathrm{w}} \geq 6.5$ earthquakes, and according to the time-dependent earthquake probability study (Pace et al., 2006, 2014, Peruzza et al., 2011), they both have high probability of producing a characteristic earthquake in the next 50 years ( 13\% for the Ovindoli-Campo Felice fault and $\sim 30 \%$ for the MagnolaVelino fault). The M. Faito fault has also accumulated positive values of $\Delta$ CFS, but its activity is still debated.

Most of the faults located in the southern part of our study region have accumulated positive cosesismic and postseismic $\triangle$ CFS due to the 1915 Fucino earthquake. The Pizzalto-Rotella-Aremogna fault system has not produced any $M \geq 5.5$ historical earthquakes, but Tesson et al. (2016) showed that at least six surfacerupturing earthquakes have occurred over the last 3,000 years on the Pizzalto fault, with the most recent event probably dated between 800 and 1700 years B.P. As for the M. Faito fault, there is no information on the Montagnola fault and about its activity. The Barrea fault system has experienced a $M_{\mathrm{w}}=5.8$ event in 1984 (Pace et al., 2002), but no paleoseismological data are available for this fault at this time. The Marsicano fault has not been associated with either historical nor paleoseismological earthquake, but it is considered as an active fault (Pace et al., 2006). Finally, the Sora fault was probably responsible for the $M_{\mathrm{w}}$ 6.3 1654 Sorano earthquake (Pace et al., 2006); however no additional information about past earthquakes is available for this fault.

Finally, we believe that the positive $\triangle$ CFS concentrated in the region south of the Fucino fault may be underestimated if we only take into account the 1915 earthquake. In fact, in 1805, a $M_{w} 6.7$ occurred in the Bojano area (Figure 1) possibly due to the rupture of the NW-SE striking Bojano normal fault (DISS Working Group, 2015). Considering the magnitude of the 1805 earthquake, the distance between the Fucino and Bojano areas $(\sim 80 \mathrm{~km})$, and 213 years of viscoelastic relaxation, all the region located between the southern termination of the 1915 rupture and the northern termination of the 1805 rupture may have accumulated values of $\Delta$ CFS larger than the ones shown in Figure 7, while only one $M_{w}>5.5$ event (Barrea earthquake) has occurred in this region in the last century. Notably, this sector corresponds to the flat section of the cumulative seismic moment curve along the Apennines, represented in Figure $3 \mathrm{~b}$, thus raising the fundamental question of whether (1) it is a seismic gap, thus capable of a potential impending major earthquake favored by the surrounding recent earthquake activity, or (2) it instead represents a less seismic zone that for structural and/or geological reasons accommodates the deformation mainly by creeping/aseismic processes or by transferring it outside the axial part of the chain. This question deserves future investigation.

\subsection{Considerations on Longer-Term Coulomb Stress Transfer Effects}

In this paper we identify several long and short-term earthquake cascades along the Apennines (Figure 3) by taking into consideration the coseismic and postseismic along-strike positive interaction among faults. However, interaction among faults can also occur with a combination of coseismic stress shadows, and postseismic stress increase, for example, has been suggested for interaction between the $1703 M_{\mathrm{w}} 6.9$ Norcia earthquake and the 2016 events on the Vettore fault. This means that we will be able to draw a complete picture of long-term seismicity patterns only when considering the combined effects of coseismic, postseismic, and interseismic $\triangle$ CFS over an entire earthquake cycle.

Recently, other authors (Mildon et al., 2017; Wedmore et al., 2017) have quantified the stress shadows (negative $\Delta$ CFS) produced by large earthquakes in this region and have shown that they can have a great impact on delaying events on neighboring faults and therefore on extending fault recurrence intervals. However, they did not consider the effect of viscoelastic stress transfer. We demonstrate that (Figure 4b) the effect of 94 years of viscoelastic postseismic $\triangle$ CFS due to the 1915 Fucino earthquake has produced a positive $\triangle C F S$ in the region surrounding the source fault. This positive contribution is not able to overcome the negative $\Delta$ CFS produced by the coseismic effects, but it represents an additional source of positive stress for those faults that experienced negative $\Delta C F S$, source fault included. 
Long-term interaction between parallel faults has not been accounted for in our study. Mildon et al. (2017), for example, assigned the $1703 M_{\mathrm{w}} 6.9$ earthquake (Valnerina area in Figure 1) to a fault located near the town of Norcia (Figure 6) and parallel to the Gorzano and Vettore faults; their results from coseismic $\Delta$ CFS modeling indicate negative $\triangle$ CFS ( -2 bars) on the Vettore fault due to the effect of the 1703 earthquake. Based on our previous considerations on the Fucino earthquake (Figure 4) and due to the relative position and distance $(\sim 12 \mathrm{~km})$ between the 1703 and the 2016 faults, we believe that more than 300 years of postseismic $\Delta C F S$ would significantly ease the negative $\triangle C F S$ accumulated on the Vettore fault. The magnitude and distribution of $\Delta$ CFS, however, depend mostly on the characteristics of the source fault (e.g., geometry and slip distribution) that for the 1703 earthquake, and in general for all preinstrumental events, are unknown.

In this work we modeled the cumulative (coseismic + postseismic) $\Delta$ CFS due to the about last 100 years of strong $\left(M_{\mathrm{w}} \geq 6\right)$ earthquakes in Central Italy. The choice of this time window is due to the fact that it is only from the 1915 Fucino earthquake that we have enough data for a reliable earthquake-to-fault association and to constrain the depth and the slip distribution on the fault we have to model. We are aware that including older events may alter our final results, but this qualitative picture can be driven by subjective choices and their uncertainties. Our purpose was to reach an accurate and plausible calculation, capable of explaining the sequence evolution in terms of quantitative values reached by the $\Delta C F S$, which is a mandatory step for including stress change models in seismic hazard assessment. This is feasible only by modeling earthquakes that were instrumentally recorded. We acknowledge that this study is still not able to define a $\triangle \mathrm{CFS}$ triggering threshold, and the pre-event stress condition of fault patches created by tectonic loading seems to control the rupture nucleation and the time of occurrence of the earthquakes. Nevertheless, all the post-1915 M6 events nucleated for fault patches with $\triangle$ CFS values greater than 0.2 bar, thus confirming the existing literature (Reasenberg \& Simpson, 1992; Stein, 1999). This work shows that viscoelastic relaxation may play a significant role in the time-dependent distribution of $\triangle$ CFS, sometimes comparable with the tectonic loading of Central Italy.

\subsection{Model Limitations}

Beyond the above shortcomings of our modeling results due to the timescale considered, we also acknowledge the fact that models based on cumulative $\triangle$ CFS calculations are characterized by uncertainties related to modeling oversimplifications and to the choice of physical parameters. The coefficient of effective friction $\left(\mu^{\prime}\right)$, which controls the change in normal stress (equation (1)), is assumed to be between 0 and 0.8 (Verdecchia \& Carena, 2015, and references therein). Because $\mu^{\prime}$ has a very small impact on both the magnitude and the pattern of stress distribution (King et al., 1994; Verdecchia \& Carena, 2015, 2016), here we consider an average value of 0.4 for all the modeled faults.

Unlike the choice of $\mu^{\prime}$, the choice of the rheological model and in particular the viscosity values in the postseismic modeling plays a significant role in the magnitude and spatial distribution of postseismic $\Delta$ CFS. Therefore, it scales with the observation made in section 2.2 that we used to identify possible long-term cascades. As already described in section 2.2, and shown in Figure S1, the model adopted in the viscoelastic calculations (Model 5 in Figure S1) is based on a Maxwell rheology, which is also used in other studies located in the same region (Amoruso et al., 2005; Aoudia et al., 2003; Riva et al., 2007). Several studies have investigated the rheological structure of the lithosphere in the western United States and in Turkey, with different models using the Maxwell rheology (Lorenzo-Martín et al., 2006; Thatcher \& Pollitz, 2008), a Burgers rheology (DeVries et al., 2016; Pollitz, 2003), and a power law rheology (Freed \& Bürgmann, 2004). Lorenzo-Martín et al. (2006) and DeVries et al. (2016), in particular, have studied the Coulomb stress evolution on the North Anatolian fault, using respectively a Maxwell and a Burgers rheology, and found no significant variation in the magnitude and spatial distribution of the stress changes. By comparing long-term geologic slip rates with geodetically derived fault slip rates of 15 continental strike-slip faults, Meade et al. (2013) concluded that a two-layer Burgers model better fit the observations of deformation over the entire earthquake cycle. More recent papers have directly imaged transient viscosity (most likely due to a biviscous Burgers rheology) in the lower crust of the region struck by the $2016 M_{\mathrm{w}} 7.1$ Kunamoto earthquake (Moore et al., 2017) and in the Sumatran mantle wedge (Qiu et al., 2018). These new results show that different rheological models may be plausible also for the central Apennines and that further investigations, possibly based on the new geodetic data available after the 2016-2017 Central Italy sequence, are necessary to better constrain the rheological parameters of the lithosphere in Central Italy. Choosing between a Maxwell or a Burgers model 
in fact can affect the time evolution of the system and as a consequence may have implications for the shortterm triggered earthquakes against the long term. Therefore, the choice of rheology will be very important when assessing potential future seismic hazard.

\section{Conclusions}

We explored the impact of time-dependent viscoelastic relaxation models to analyze the seismicity of Central Italy, with a special focus on the 2016-2017 sequence. Only reliable fault geometries and instrumental slip distributions have been used to compute the cumulative static stress change histories at some hypocentral locations. Considering the space-time evolution of the seismicity at the regional (Central Apennines) and local (single fault) scale, as presented in the results and discussion above, we have reached the following conclusions:

1. At diffuse plate boundaries, and slowly deforming regions such as Central Italy, where we expect strongto-major earthquakes ( $M \sim 7$, recurrence time of $\sim 1,000$ years), postseismic effects have a significant role in the long-term evolution (100-year timescale) of the seismicity on a 70-km spatial scale; coseismic effects play a major role at small temporal and spatial scales (10 years and max $40 \mathrm{~km}$ ).

2. Long-term and short-term earthquake cascades can be identified along the central Apennines, following the rules of theoretical models; the last one probably started with the $1915 M_{\mathrm{w}} 6.9$ Fucino earthquake and is potentially still ongoing. In this cascades, Fucino postseismic $\Delta$ CFS favored the 2009 L'Aquila earthquake, which in turn promoted the most recent events of 2016, while from the north, concurrent contribution to failure is given by the 1997 earthquakes.

3. The stress changes at successive hypocenters obtained by 103 years of coseismic plus postseismic $\Delta C F S$ modeled in this work always exceed the literature threshold of 0.2 bar: the pre-event stress conditions of different segments cannot be quantitatively modeled, but they may be responsible of the timing of failure. These considerations pose a severe limitation to the translation of static stress changes values into seismicity rates, as required for seismic hazard assessment.

4. Our coseismic and postseismic stress modeling, in addition to the historical and paleoseismological data available in our study region, allowed us to suggest that the Gorzano fault has been strongly loaded by the 1915, the 2009, and the 2016-2017 earthquakes.

5. Several other active faults, north and south of the Fucino plain, may at present also be close to failure: further investigations are needed in the area north of Bojano, to better understand the nature of the deficit of seismic moment.

6. Future efforts should focus on considering both coseismic and postseismic processes in fault-based seismic hazard models.

\section{References}

Ali, S. T., Freed, A. M., Calais, E., Manaker, D. M., \& McCann, W. R. (2008). Coulomb stress evolution in Northeastern Caribbean over the past 250 years due to coseismic, postseismic and interseismic deformation. Geophysical Journal International, 174(3), 904-918. https://doi.org/ $10.1111 /$ j.1365-246X.2008.03634.X

Amoruso, A., Crescentini, L., D'Anastasio, E., \& De Martini, P. M. (2005). Clues of postseismic relaxation for the 1915 Fucino earthquake (Central Italy) from modeling of leveling data. Geophysical Research Letters, 32, L22307. https://doi.org/10.1029/2005GL024139

Amoruso, A., Crescentini, L., \& Scarpa, R. (1998). Inversion of source parameters from near- and far-field observations: An application to the 1915 Fucino earthquake, central Apennines, Italy. Journal of Geophysical Research, 103, 29,989-29,999. https://doi.org/10.1029/ 98JB02849

Antonioli, A., Piccinini, D., Chiaraluce, L., \& Cocco, M. (2005). Fluid flow and seismicity pattern: Evidence from the 1997 Umbria-Marche (Central Italy) seismic sequence. Geophysical Research Letters, 32, L10311. https://doi.org/10.1029/2004GL022256

Aoudia, A., Borghi, A., Riva, R., Barzaghi, R., Ambrosius, B. A. C., Sabadini, R., et al. (2003). Postseismic deformation following the 1997 UmbriaMarche (Italy) moderate normal faulting earthquakes. Geophysical Research Letters, 30(7), 1390. https://doi.org/10.1029/2002GL016339

Benedetti, L. (1999). Sismotectonique de I'Italie et des regions adjacentes: Fragmentation du promontoire adriatique, These de doctorat IPGP - Université Paris 7.

Benedetti, L., Manighetti, I., Gaudemer, Y., Finkel, R., Malavieille, J., Pou, K., et al. (2013). Earthquake synchrony and clustering on Fucino faults (Central Italy) as revealed from in situ ${ }^{36} \mathrm{Cl}$ exposure dating. Journal of Geophysical Research: Solid Earth, 118, 4948-4974. https://doi.org/ 10.1002/jgrb.50299

Bhat, H. S., Olives, M., Dmowska, R., \& Rice, J. R. (2007). Role of fault branches in earthquake rupture dynamics. Journal of Geophysical Research, 112, B11309. https://doi.org/10.1029/2007JB005027

Biemiller, J., \& Lavier, L. (2017). Earthquake supercycles as part of a spectrum of normal fault slip styles. Journal of Geophysical Research: Solid Earth, 122, 3221-3240. https://doi.org/10.1002/2016JB013666

Boncio, P., Lavecchia, G., \& Pace, B. (2004). Defining a model of 3D seismogenic sources for seismic hazard assessment applications: The case of central Apennines (Italy). Journal of Seismology, 8(3), 1027-1047. 
Chartier, T., Scotti, O., Clément, C., Jomard, H., \& Baize, S. (2017). Transposing an active fault database into a fault-based seismic hazard assessment for nuclear facilities - Part 2: Impact of fault parameter uncertainties on a site-specific PSHA exercise in the Upper Rhine Graben, eastern France. Natural Hazards and Earth System Sciences, 17(9), 1585-1593. https://doi.org/10.5194/nhess-17-1585-2017

Cheloni, D., Giuliani, R., D'Anastasio, E., Atzori, S., Walters, R. J., Bonci, L., et al. (2014). Coseismic and post-seismic slip of the 2009 L'Aquila (central Italy) $M_{\mathrm{w}} 6.3$ earthquake and implications for seismic potential along the Campotosto fault from joint inversion of high-precision levelling, InSAR and GPS data. Tectonophysics, 622, 168-185. https://doi.org/10.1016/j.tecto.2014.03.009

Chéry, J., Carretier, S., \& Ritz, J. F. (2001). Postseismic stress transfer explains time clustering of large earthquakes in Mongolia. Earth and Planetary Science Letters, 97, 277-286.

Chiarabba, C., De Gori, P., \& Amato, A. (2011). Do earthquake storms repeat in the Apennines of Italy? Terra Nova, 23(5), 300-306. https://doi. org/10.1111/j.1365-3121.2011.01013.x

Chiaraluce, L., Di Stefano, R., Tinti, E., Scognamiglio, L., Michele, M., Casarotti, E., et al. (2017). The 2016 Central Italy seismic sequence: A first look at the mainshock, aftershocks, and source models. Seismological Research Letters, 88(3), 757-771. https://doi.org/10.1785/ 0220160221

Chiaraluce, L., Valoroso, L., Piccinini, D., Di Stefano, R., \& De Gori, P. (2011). The anatomy of the 2009 L'Aquila normal fault system (Central Italy) imaged by high resolution foreshock and aftershock locations. Journal of Geophysical Research, 116, B12311. https://doi.org/10.1029/ 2011 JB008352

Console, R., Murru, M., Falcone, G., \& Catalli, F. (2008). Stress interaction effect on the occurrence probability of characteristic earthquakes in Central Appennines. Journal of Geophysical Research, 113, B08313. https://doi.org/10.1029/2007JB005418

Cowie, P. A. (1998). A healing-reloading feedback control on the growth rate of seismogenic faults. Journal of Structural Geology, 20(8), 1075-1087. https://doi.org/10.1016/S0191-8141(98)00034-0

Davy, P., Hansen, A., Bonnet, E., \& Zhang, S.-Z. (1995). Localization and fault growth in layered brittle-ductile systems: Implications for deformations of the continental lithosphere. Journal of Geophysical Research, 100, 6281-6294. https://doi.org/10.1029/94JB02983

DeVries, P. M. R., Krastev, P. G., \& Meade, B. J. (2016). Geodetically constrained models of viscoelastic stress transfer and earthquake triggering along the North Anatolian fault. Geochemistry, Geophysics, Geosystems, 17, 2700-2716. https://doi.org/10.1002/2016GC006313

DISS Working Group. (2015). Database of individual seismogenic sources (DISS), version 3.2.0: A compilation of potential sources for earthquakes larger than M 5.5 in Italy and surrounding areas. http://diss.rm.ingv.it/diss, Istituto Nazionale di Geofisica e Vulcanologia, doi: https://doi.org/10.6092/INGV.IT-DISS3.2.0

Dolan, J. R., McAuliffe, L. J., Rhodes, E. J., McGill, S. F., \& Zinke, R. (2016). Extreme multi-millennial slip rate variations on the Garlock fault, California: Strain super-cycles, potentially time-variable fault strength, and implications for system-level earthquake occurrence. Earth and Planetary Science Letters, 446, 123-136. https://doi.org/10.1016/j.epsl.2016.04.011

Faenza, L., Marzocchi, W., Lombardi, A. N., \& Console, R. (2004). Some insights into the time clustering of large earthquakes in Italy. Annals of Geophysics-Italy, 47(5), 1635-1640.

Falcucci, E., Gori, S., Moro, M., Pisani, A. R., Melini, D., Galadini, F., \& Fredi, P. (2011). The 2009 L'Aquila earthquake (Italy): What's next in the region? Hints from stress diffusion analysis and normal fault activity. Earth and Planetary Science Letters, 305(3-4), 350-358. https://doi.org/ 10.1016/j.epsl.2011.03.016

Field, E. H., Biasi, G. P., Bird, P., Dawson, T. E., Felzer, K. R., Jackson, D. D., et al. (2015). Long-term time-dependent probabilities for the third uniform California earthquake rupture forecast (UCERF3). Bulletin of the Seismological Society of America, 105(2A), 511-543. https://doi.org/ $10.1785 / 0120140093$

Freed, A. M. (2005). Earthquake triggering by static, dynamic and postseismic stress transfer. Annual Review of Earth and Planetary Sciences, 33(1), 335-367. https://doi.org/10.1146/annurev.earth.33.092203.122505

Freed, A. M., \& Bürgmann, R. (2004). Evidence of power-law flow in the Mojave Desert mantle. Nature, 430(6999), 548-551. https://doi.org/ 10.1038/nature02784

Friedrich, A. M., Wernicke, B. P., Niemi, N. A., Bennett, R. A., \& Davis, J. L. (2003). Comparison of geodetic and geologic data from the Wasatch region, Utah, and implications for the spectral character of Earth deformation at periods of 10 to 10 million years. Journal of Geophysical Research, 108(B4), 2199. https://doi.org/10.1029/2001JB000682

Gallovič, F., Imperatori, W., \& Mai, P. M. (2015). Effects of three-dimensional crustal structure and smoothing constraint on earthquake slip inversion: Case study of the $M_{\mathrm{w}} 6.32009$ L'Aquila earthquake. Journal of Geophysical Research: Solid Earth, 120, 428-449. https://doi.org/ 10.1002/2014JB011650

Gold, R. D., Cowgill, E., Arrowsmith, J. R., \& Friedrich, A. M. (2017). Pulsed strain release on the Altyn Tagh fault, northwest China. Earth and Planetary Science Letters, 459, 291-300. https://doi.org/10.1016/j.epsl.2016.11.024

Gülerce, Z., Shah, S. T., Manekşe, A., Özacar, A. A., Kaymakci, N., \& Çetin, K. O. (2017). Probabilistic seismic-hazard assessment for East Anatolian fault zone using planar fault source models. Bulletin of the Seismological Society of America, 107(5), 2353-2366. https://doi.org/ $10.1785 / 0120170009$

Hanks, T. C. (1977). Earthquake stress drops, ambient tectonic stresses and stresses that drive plate motions. Pure and Applied Geophysics, 115 $441-458$

Harris, R. A., \& Simpson, R. W. (1998). Suppression of large earthquakes by stress shadows; A comparison of Coulomb and rate-and-state failure. Journal of Geophysical Research, 103, 19,835-19,858. https://doi.org/10.1029/98JB00793

Hernandez, B., Cocco, M., Cotton, F., Stramondo, S., Scotti, O., Courboulex, F., \& Campillo, M. (2004). Rupture history of the 1997 UmbriaMarche (Central Italy) main shocks from the inversion of GPS, DInSAR and near field strong motion data. Annals of Geophysics-Italy, 47(4), $1355-1377$

King, G. C. P., \& Cocco, M. (2001). Fault interaction by elastic stress changes: New clues from earthquake sequences. Advances in Geophysics, 44, 1-38. https://doi.org/10.1016/S0065-2687(00)80006-0

King, G. C. P., Stein, R. S., \& Lin, J. (1994). Static stress changes and the triggering of earthquakes. Bulletin of the Seismological Society of America, 84, 935-953.

Laske, G., Masters, G, Ma, Z., \& Pasyanos, M. (2013). Update on CRUST1.0 - A 1-degree global model of Earth's crust, Geophys. Res. Abstracts, 15, Abstract EGU2013-2658.

Lorenzo-Martín, F., Roth, F., \& Wang, R. J. (2006). Elastic and inelastic triggering of earthquakes in North Anatolian Fault zone. Tectonophysics, 424(3-4), 271-289. https://doi.org/10.1016/j.tecto.2006.03.046

Ma, K. F., Chan, C. H., \& Stein, R. S. (2005). Response of seismicity to Coulomb stress triggers and shadows of the $1999 M_{w}=7.6$ Chi-Chi, Taiwan, earthquake. Journal of Geophysical Research, 110, B05S19. https://doi.org/10.1029/2004JB003389

Marsan, D. (2003). Triggering of seismicity at short timescales following Californian earthquakes. Journal of Geophysical Research, 108(B5), 2266. https://doi.org/10.1029/2002JB001946 
Meade, B. J., Klinger, Y., \& Hetland, E. A. (2013). Influence of multiple earthquake-cycle relaxation timescales from irregular geodetic sampling of interseismic deformation. Bulletin of the Seismological Society of America, 103(5), 2824-2835. https://doi.org/10.1785/0120130006

Mildon, Z. K., Roberts, G. P., Faure Walker, J. P., \& lezzi, F. (2017, 210). Coulomb stress transfer and fault interaction over millennia on nonplanar active normal faults: The $M_{\mathrm{w}} 6.5-5.0$ seismic sequence of 2016-2017, Central Italy. Geophysical Journal International, 210(2), 1206-1218. https://doi.org/10.1093/gji/ggx213

Moore, J. D. P., Yu, H., Tang, C.-H., Wang, T., Barbot, S., Peng, D., et al. (2017). Imaging the distribution of transient viscosity after the $2016 M_{w}$ 7.1 Kunamoto earthquake. Science, 356(6334), 163-167. https://doi.org/10.1126/science.aal3422

Pace, B., Bocchini, G. M., \& Boncio, P. (2014). Do static stress changes of a moderate-magnitude earthquake significantly modify the regional seismic hazard? Hints from the L'Aquila 2009 normal-faulting earthquake ( $M_{\mathrm{w}}$ 6.3, Central Italy). Terra Nova, 26(6), 430-439. https://doi. org/10.1111/ter.12117

Pace, B., Boncio, P., \& Lavecchia, G. (2002). The 1984 Abruzzo earthquake (Italy): An example of seismogenic process controlled by interaction between differently oriented synkinematic faults. Tectonophysics, 350(3), 237-254. https://doi.org/10.1016/S0040-1951(02)00118-X

Pace, B., Peruzza, L., Lavecchia, G., \& Boncio, P. (2006). Layered seismogenic source model and probabilistic seismic-hazard analyses in Central Italy. Bulletin of the Seismological Society of America, 96(1), 107-132. https://doi.org/10.1785/0120040231

Pantosti, D., D'Addezio, G., \& Cinti, F. R. (1996). Paleoseismicity of the Ovindoli-Pezza fault, central Apennines, Italy: A history including a large, previously unrecorded earthquake in the Middle ages (860-1300 A.D.). Journal of Geophysical Research, 101, 5937-5959. https://doi.org/ 10.1029/95JB03213

Paolucci, R., Evangelista, L., Mazzieri, I., \& Schiappapietra, E. (2016). The 3D numerical simulation of near-source ground motion during the Marsica earthquake, Central Italy, 100 years later. Soil Dynamics and Earthquake Engineering, 91, 39-52. https://doi.org/10.1016/j. soildyn.2016.09.023

Parsons, T., Toda, S., Stein, R. S., Barka, A., \& Dieterich, J. H. (2000). Heightened odds of large earthquakes near Istanbul: An interaction-based probability calculation. Science, 288(5466), 661-665. https://doi.org/10.1126/science.288.5466.661

Peruzza, L., Pace, B., \& Visini, F. (2011). Fault-based earthquake rupture forecast in central Italy: Remarks after the L'Aquila Mw 6.3 event. Bulletin of the Seismological Society of America, 101(1), 404. https://doi.org/10.1785/0120090276

Pollitz, F. F. (2003). Transient rheology of the uppermost mantle beneath the Mojave Desert, California. Earth and Planetary Science Letters, 215(1-2), 89-104. https://doi.org/10.1016/S0012-821X(03)00432-1

Pollitz, F. F., Vergnolle, M., \& Calais, E. (2003). Fault interaction and stress triggering of 20th century earthquakes in Mongolia. Journal of Geophysical Research, 108(B10), 2503. https://doi.org/10.1029/2002JB002375

Qiu, Q., Moore, J. D. P., Barbot, S., Feng, L., \& Hill, E. M. (2018). Transient rheology of the Sumatran wedge revealed by a decade of great earthquakes. Nature Communications, 9(1), 995. https://doi.org/10.1038/s41467-018-03298-6

Reasenberg, P. A., \& Simpson, R. W. (1992). Response of regional seismicity to the static stress change produced by the Loma-Prieta earthquake. Science, 255(5052), 1687-1690. https://doi.org/10.1126/science.255.5052.1687

Riva, R. E. M., Borghi, A., Aoudia, A., Barzaghi, R., Sabadini, R., \& Panza, G. F. (2007). Viscoelastic relaxation and long-lasting after-slip following the 1997 Umbria-Marche (Central Italy) earthquakes. Geophysical Journal International, 169(2), 534-546. https://doi.org/10.1111/j.1365246X.2007.03315.x

Robinson, R. (2004). Potential earthquake triggering in a complex fault network: The northern South Island, New Zealand. Geophysical Journal International, 159(2), 734-748. https://doi.org/10.1111/j.1365-246X.2004.02446.x

Rovida, A., Locati, M., Camassi, R., Lolli, B., \& Gasperini, P. (Eds.) (2016). CPTI15, the 2015 version of the parametric catalogue of Italian earthquakes. Istituto Nazionale di Geofisica e Vulcanologia. https://doi.org/10.6092/INGV.IT-CPTI15

Schlagenhauf, A., Manighetti, I., Benedetti, L., Gaudemer, Y., Finkel, R., Malavieille, J., \& Pou, K. (2011). Earthquake supercycles in Central Italy, inferred from ${ }^{36} \mathrm{Cl}$ exposure dating. Earth and Planetary Science Letters, 307(3-4), 487-500. https://doi.org/10.1016/j. epsl.2011.05.022

Scholz, C. H. (2002). The mechanism of earthquake and faulting, (2nd ed.). New York: Cambridge Univ. Press. https://doi.org/10.1017/ CBO9780511818516

Scholz, C. H. (2010). Large earthquakes triggering, clustering, and the synchronization of faults. Bulletin of the Seismological Society of America, 100(3), 901-909. https://doi.org/10.1785/0120090309

Scholz, C. H., \& Gupta, A. (2000). Fault interactions and seismic hazard. Journal of Geodynamics, 29(3-5), 459-467. https://doi.org/10.1016/ S0264-3707(99)00040-X

Scognamiglio, L., Tinti, E., Michelini, A., Dreger, D. S., Cirella, A., Cocco, M., et al. (2010). Fast determination of moment tensors and rupture history: What has been learned from the 6 April 2009 L'Aquila earthquake sequence. Seismological Research Letters, 81(6), 892-906. https:// doi.org/10.1785/gssrl.81.6.892

Shan, B., Xiong, X., Wang, R., Zheng, Y., \& Yang, S. (2013). Coulomb stress evolution along Xianshuihe-Xiaojiang Fault System since 1713 and its interaction with Wenchuan earthquake, May 12, 2008. Earth and Planetary Science Letters, 377-378, 199-210. https://doi.org/10.1016/j. epsl.2013.06.044

Sieh, K., Natawidjaja, D. H., Meltzner, A. J., Shen, C.-C., Cheng, H., Li, K.-S., et al. (2008). Earthquake supercycles inferred from sea-level changes recorded in the corals of west Sumatra. Science, 322(5908), 1674-1678. https://doi.org/10.1126/science.1163589

Sornette, A., Davy, P., \& Sornette, D. (1990). Growth of fractal fault patterns. Physical Review Letters, 65(18), 2266-2269. https://doi.org/ 10.1103/PhysRevLett.65.2266

Sornette, D., Davy, P., \& Sornette, A. (1990). Structuration of the lithosphere in plate tectonics as a self-organized critical phenomenon. Journal of Geophysical Research, 95, 17,353-17,361. https://doi.org/10.1029/JB095iB11p17353

Stein, R. S. (1999). The role of stress transfer in earthquake occurrence. Nature, 402(6762), 605-609. https://doi.org/10.1038/45144

Stein, R. S., Barka, A. A., \& Dieterich, J. H. (1997). Progressive failure on the North Anatolian fault since 1939 by earthquake stress triggering Geophysical Journal International, 128(3), 594-604. https://doi.org/10.1111/j.1365-246X.1997.tb05321.x

Stein, R. S., King, G. C. P., \& Lin, J. (1992). Change in failure stress on the southern San Andreas fault system caused by the 1992 magnitude $=$ 7.4 Landers earthquake. Science, 258(5086), 1328-1332. https://doi.org/10.1126/science.258.5086.1328

Stein, R. S., King, G. C. P., \& Lin, J. (1994). Stress triggering of the $1994 M=6.7$ Northridge, California earthquake by its predecessors. Science, 258, 1328-1332.

Tesson, J., Pace, B., Benedetti, L., Visini, F., Rocioli, D., Arnold, M., et al. (2016). Seismic slip history of the Pizzalto fault (central Apennines, Italy) using in situ-produced ${ }^{36} \mathrm{Cl}$ cosmic ray exposure dating and rare earth element concentrations. Journal of Geophysical Research: Solid Earth, 121, 1983-2003. https://doi.org/10.1002/2015JB012565

Thatcher, W., \& Pollitz, F. F. (2008). Temporal evolution of continental lithospheric strength in actively deforming regions. GSA Today, 18(4), 4-11. https://doi.org/10.1130/GSAT01804-5A.1 
Tinti, E., Scognamiglio, L., Michelini, A., \& Cocco, M. (2016). Slip heterogeneity and directivity of the $M_{\mathrm{L}} 6.0,2016$, Amatrice earthquake estimated with rapid finite-fault inversion. Geophysical Research Letters, 43, 10,745-10,752. https://doi.org/10.1002/2016GL071263

Toda, S., Lin, J., Meghraoui, M., \& Stein, R. S. (2008). 12 May 2008 M = 7.9 Wenchuan, China, earthquake calculated to increase failure stress and seismicity rate on three major fault systems. Geophysical Research Letters, 35, L17305. https://doi.org/10.1029/2008GL034903

Toda, S., Stein, R. S., Sevileg, V., \& Lin, J. (2011). Coulomb 3.3 graphic-rich deformation and stress change software for earthquake, tectonic, and volcano research and teaching - User guide. U.S. Geological Survey Open-File Report, 63, 2011-1060.

Valentini, A., Visini, F., \& Pace, B. (2017). Integrating faults and past earthquakes into a probabilistic seismic hazard model for peninsular Italy Natural Hazards and Earth System Sciences, 17(11), 2017-2039. https://doi.org/10.5194/nhess-17-2017-2017

Verdecchia, A., \& Carena, S. (2015). One hundred and fifty years of Coulomb stress history along the California-Nevada border, USA. Tectonics, 34, 213-231. https://doi.org/10.1002/2014TC003746

Verdecchia, A., \& Carena, S. (2016). Coulomb stress evolution in a diffuse plate boundary: 1400 years of earthquakes in eastern California and western Nevada, USA. Tectonics, 35, 1793-1811. https://doi.org/10.1002/2015TC004091

Visini, F., \& Pace, B. (2014). Insights on a key parameter of earthquake forecasting, the coefficient of variation of the recurrence time, using a simple earthquake simulator. Seismological Research Letters, 85(3), 703-713. https://doi.org/10.1785/0220130165

Wang, R., Lorenzo-Martín, F., \& Roth, F. (2006). PSGRN/PSCMP - A new code for calculating co- and post-seismic deformation, geoid and gravity changes based on the viscoelastic-gravitational dislocation theory. Computers and Geosciences, 32(4), 527-541. https://doi.org/ 10.1016/j.cageo.2005.08.006

Ward, S. N. V., \& Valensise, G. (1989). Fault parameters and slip distribution of the 1915 Avezzano, Italy, earthquake derived from geodetic observations. Bulletin of the Seismological Society of America, 79, 690-710.

Wedmore, L. N. J., Faure Walker, J. P., Roberts, G. P., Sammonds, P. R., McCaffrey, K. J. W., \& Cowie, P. A. (2017). A 667 year record of coseismic and interseismic Coulomb stress changes in Central Italy reveals the role of fault interaction in controlling irregular earthquake recurrence intervals. Journal of Geophysical Research: Solid Earth, 122, 5691-5711. https://doi.org/10.1002/2017JB014054

Wells, D. L., \& Coppersmith, K. J. (1994). New empirical relationship among magnitude, rupture length, rupture width, rupture area, and surface displacement. Bulletin of the Seismological Society of America, 84, 974-1002. 